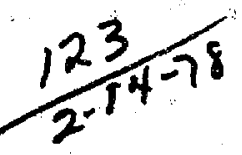

\title{
PLANE SHOCK WAVE STUDIES OF GEOLOGIC MEDIA
}

G.D. Anderson

D. 3. Larson

\section{MSTL留}

October 31, 1977

Prepared for U.S. Energy Research \& Development Administration under contract No. W-7405-Eng-48
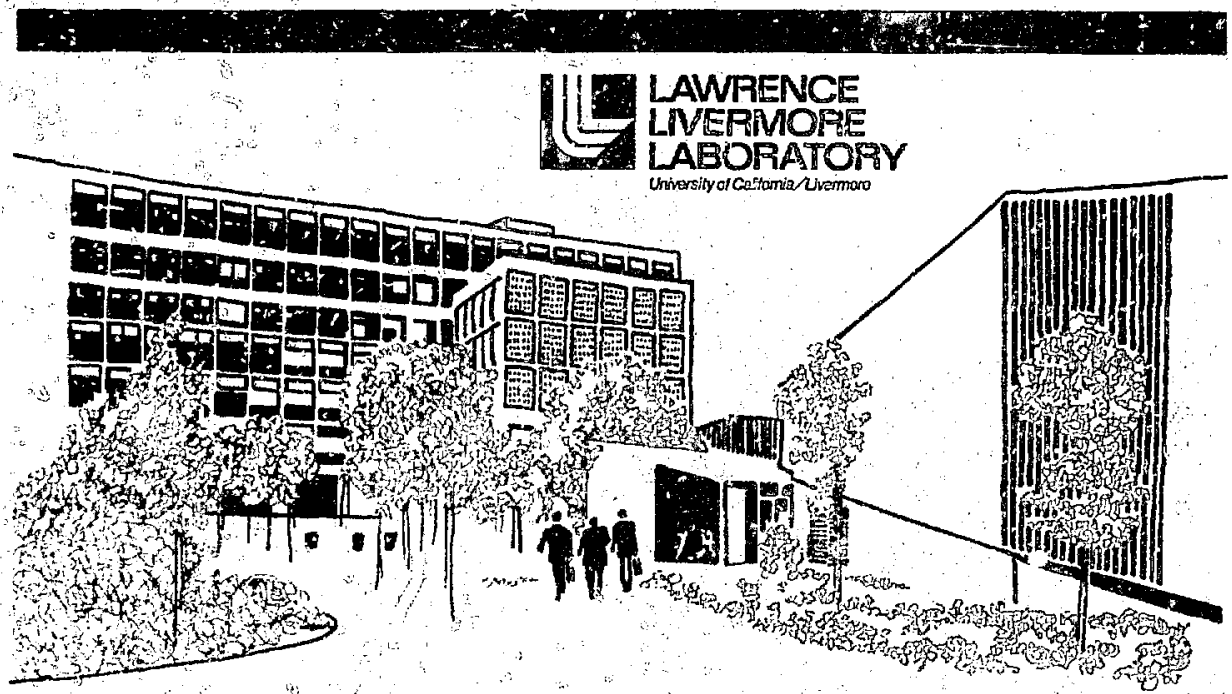

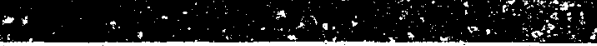




\title{
近
}

\section{LAWRENCE LIVERMORE LABORATORY}

University of Cabtonia Livarmore Califomia /94550

UCRL-5236?

\section{PLANE SHOCK WAVIS STUDIES OF GEOLOGIC MEDIA}

\author{
G. D. Anderson
}

D. B. Larson

MS date: October 31, 1977

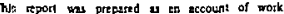
rponkared by the United Seotes Goremrent. Netther the Unitrd Sutes not the Unlted Stutes Deputment of

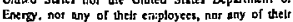
Energy, nor any of thets exiployees, nor any of thetr conimeton, suberentactor, of theis employech, maks

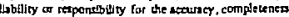
or usefulnes of any unformation, eppenitus, product or proces duclored, of tepresent that its ue would not Laferist pintebly owned ingli. 


\section{CONTENTS}

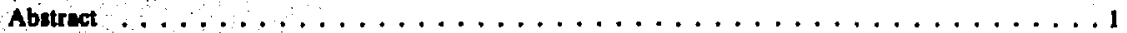

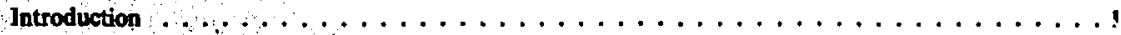

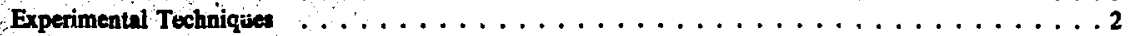

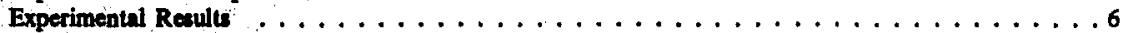

Wetterly Granite ... . . . . . . . . . . . . . . . . . . 6

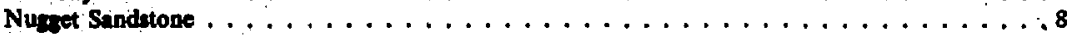

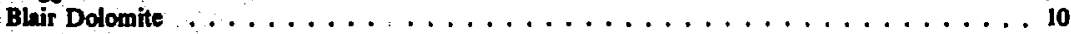

Polyeryatalline Sodium Chloride . . . . . . . . . . . . . . . . . . 12

Dry Mt. Helen Tuff . . . . . . . . . . . . . . . . . . . . . . 12

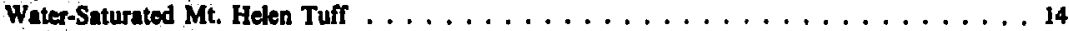

Dry Indiana Limestone ... . . . . . . . . . . . . . . . . . . . 17

Water-Saturated Indiana Limestone ....................... 17

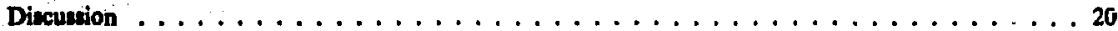

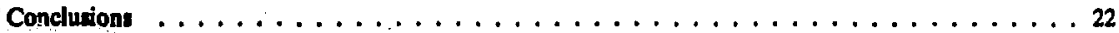

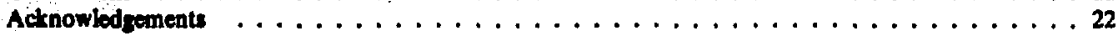

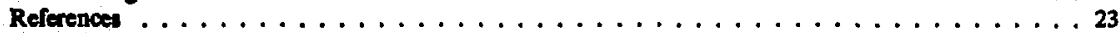




\section{PLANE SHOCK WAVE STUDIES \\ OF GEOLOGIC MEDIA}

\section{ABSTRACT}

Plane shock wave experiments have been conducted on eight geologic materials in an effort to determine the importance of time-dependent mechanical behavior. Of the eight rocks studied, only Westerly granite and nugget sandstone appear to show time independence. In the slightly porous materials (1-5\%), Blair dolomite and sodium chloride, and in the highly porous (15-40\%) rock, Mt. Helen tuff and Indiana limestone, time-dependent behavior is associated with the time required to close the available porosity. In water-saturated rocks the time dependence arises because the water that is present shows no indication of transformation to the higher pressure ice phases, thus suggesting the possibility that a metastable form of water exists under dynamic conditions.

\section{INTRODUCTION}

Experimental descriptions of the mechanical properties of geologic materials usually isclude data obtained from quasi-static, acoustic and shock wave tests. These data form the batis for constitutive models used in computer calculations to test computer simulation. The Lawrence Livermore Laboratory's seismic monitoring program uses this overall approach as one means of developing relative coupling efficiencies and/or seismic source functions for a variety of geologic materials. These source functions would provide the tasis for calculation of source spectra as a function of material properties and, given the proper transfer function, would allow a calculation of the giound motion at any seismic station.

The physical processes involved in the initiation of ecismic waves by explosions in geologic materials are very complex. Many important nonlinear processes, such as melting, polymorphism, material failure, and crushing of pores, take place before energy is coupled into the "elastic" region. Some of these nonlinear procesues are time dependent and, because the in situ events that we are trying to sinulate are dynamic, require a messurement of the characterintic time or rate constents for the proces. Therefore, as part of the effort to search for time-dependent effects, plane shock wave experi- ments were conducted on the eight materials listed in Table 1. Additional plane shock wave data on coal and siveral frozen materials appear in two publications, Shock Wave Studies of Subbituminous Coals ${ }^{1}$ by Anderson and Larson, and Shock Wave Studies of Ice and Two Frozen Soils ${ }^{2}$ by Larson, Bearson and Taylor.

Plane shock wave experiments provide data at extremely high strain rates $\left(10^{5}-10^{7} \mathrm{sec}^{-1}\right)$ and nor mally allow less than $10 \mu \mathrm{s}$ of observation time under loaded conditions, i.e., incubation time (see Fig. 1). Consequently, these tests are sensitive to some processes that are time dependent, such as phase transformations, pore collapse, ets., and thus could provide valuable insight into the mechanisms of these processes. In most seismic monitoring applications, such as nuclear or high explosive events in situ, the lispersive nature of the medium and the size of the energy source lead to strain rates in the range of $10-10^{5} \mathrm{sec}^{-1}$ and incubation times on the order of milliseconds. These rates and times are much different from those observed in laboratory seale, shock wave experiments. Nevertheless, the characteristic times or rate constants otwerved in shock wave experiments, together with quasi-static data, should provide valuabie guidelines for use in the various applications. 
Tabie 1. Propentes of the polowe matorils under anbient conditions.

\begin{tabular}{|c|c|c|c|c|}
\hline Coologe matorid & $\begin{array}{c}\text { Bulk } \\
\text { dencity } \\
\left(\mathrm{Mg} / \mathrm{m}^{3}\right)\end{array}$ & $\begin{array}{c}\text { Totel } \\
\text { parocity } \\
\text { (\%) }\end{array}$ & $\begin{array}{c}\text { Dry } \\
\text { porouity } \\
\text { (\%) }\end{array}$ & $\begin{array}{l}\text { Longitudinal } \\
\text { wound speed } \\
(\mathrm{km} / \mathrm{s})\end{array}$ \\
\hline Wanty groulte (dy) & 2.65 & 1 & $\mathbf{1}$ & 4.8 \\
\hline$N$ Nist andones $(d r y)$ & 2.42 .2 .55 & 49 & 49 & $\begin{array}{l}3.4 \text { ( } 1 \text { to bedding } \\
\text { pinne) }\end{array}$ \\
\hline Bleit dalomits (dy) & 2.84 & 1 & 1 & 5.0 \\
\hline Polyaytaria Nad (dy) & 2.13 & 1.6 & 1.6 & 4.1 \\
\hline Mt. Hater ant (dry) & 1.46 & 40 & 40 & $25-2.7$ \\
\hline Mt. Filen tuff (nrd) & 1.86 & 40 & 2 & 2.6 \\
\hline Indhen veotoun (dy) & 2.28 & 16 & 16 & 4.2 \\
\hline 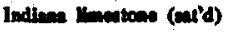 & $2.41-2.48$ & $14-20$ & o & 4.4 \\
\hline
\end{tabular}

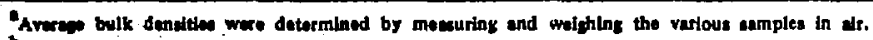

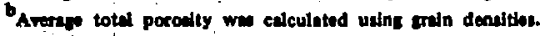

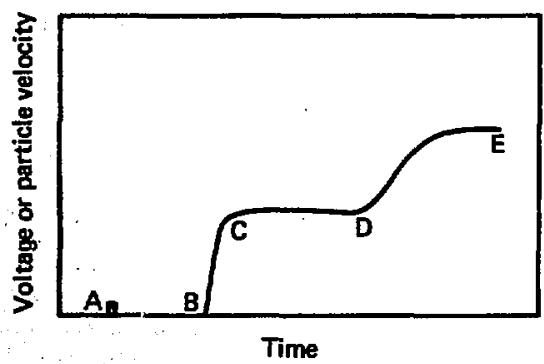

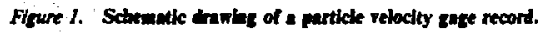
The trow C to D b inceriation time.

\section{EXPERIMENTAL TECHNIQUES}

We conducted shock wave experiments usirg a light-gas gun so that the test material was loaded under uniaxial atrain. With this gas-gun technique, flat-faced projectiles are accelerated with expanding betium gas and allowed to impact a target composed of plates of the test material; as shown chemativally in Figs. 2 and 3. In this way, the shock weve produced by the projectile impact loads the ample; coveral microseconds later, a rarefaction from the free surface cauies unloeding, whereby the tert material is relaxed to ambient stress conditions: Becauve of the reometry of these experiements, both loading ind unlonding procoses take place under conditions of uniexial strin.

We ived dingnostic zages of thin $\left(2.5 \times 10^{-2} \mathrm{~mm}\right)$ brass foils. These foils were placed on the surfaces and also sandwiched between the plates of the target material. Because the gages were thin, they equilibrated to the surrcunding material velocity in nanoseconds, thus following the motion of the sample material as both loading and unloading occurred. The foils were also constrained to move perpendicular to the magnetic field produced by a large external electromagnet. Under these conditions, the particle velocity-time history, $U_{p}(t)$, is proportional to the recorded electromotive force, $\epsilon(t)$ :

$$
U_{p}(t)=e(t) / B L
$$

where $B$ is the magnetic field strength and $L$ is the gage element length. During the fabrication of the experimental assemblies, the gages were placed on 


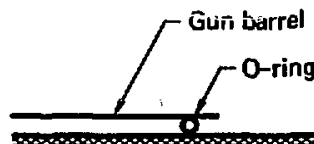

\section{Projectile}
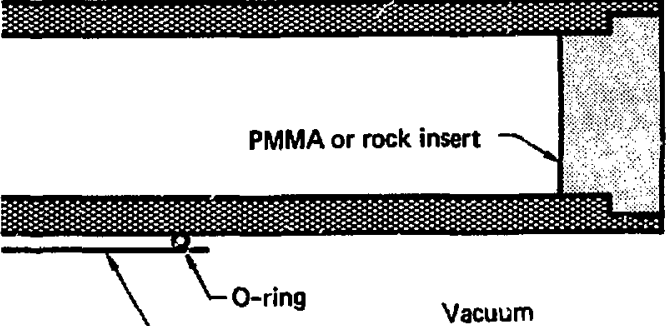

Gun barrel

Vacuum
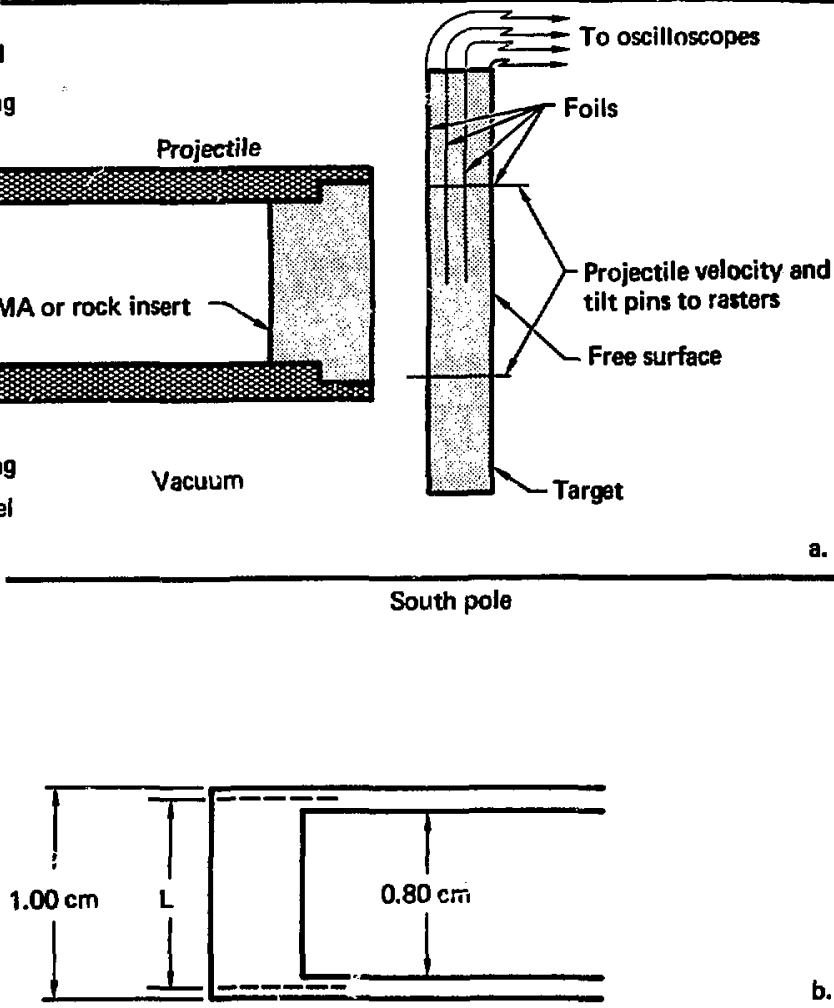

b.

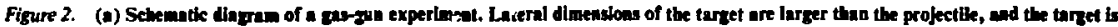

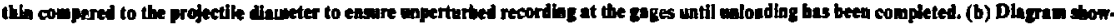
Ins the efiective kesth $L$ of the bras foll ased in the partiele velocity gage. The value, determined in four experiments $b 0.899 \mathrm{~cm} \pm 1 \%$.

carefully machined surfaces (flat and parallel to approximately $0.0025 \mathrm{~cm}$ ) of plates of the geologic material. In dry rocks, epoxy was used as a bonding agent to hold the plates together and to fill the voids between plates. In the water-saturated materials, water was used to fill the small air gaps between plates, and the plates were held together mechanically by the taryet assf.nbly. In general, the projectile inserts were made of polymethyl methacrylat; (PMMA), but for the higher impedance ruck, projectile inserts of the same rock as the target material were used to provide a greater stress range. The configuration shown in Fig. 2 was used for dry target material, and an enclosed target assembly shown in Fig. 3 was ased for saturated samples to prevent water loss. In the enclosed assemblies, a yoid between the rear plate of the rock and the rear of the target assembly provided the free surface conditions necessary to unload the sample in uriaxial strain.

The characteristics of a typical particle velocitytime profile, recorded by a particle velocity gage, are shown schematically in Fig. 1. The ordinate is cither voltage, as reconded on film from an oscilloscope trace, or the corresponding particle velocity obtained by reducing the data using Eq. (1). In either case, the abscissa is time. The pulse at $A$ is a fiducial mark which is simultaneously recorded on each oscilloscope record, so that times can be correlated between the several gages recording a 


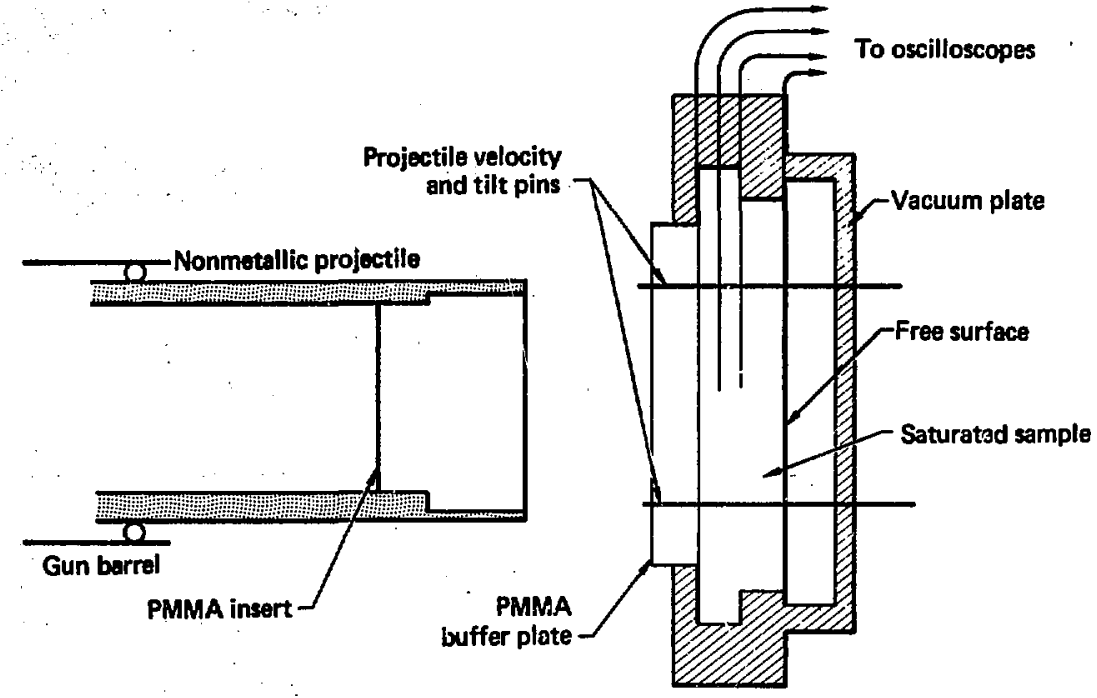

South pole

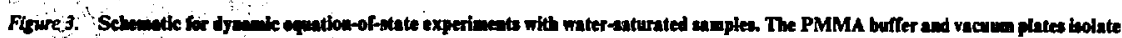

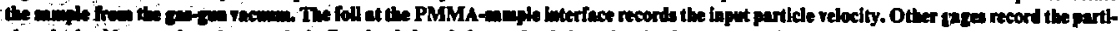

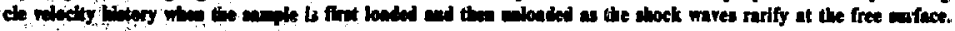

given experiment. $A t$ point $B$, the shock wave arrives at the gage and imparts to it a velocity of magnitude $C$. From timc $C$ to time $D$, the gage moves with a constant velocity while the shock front itelf kns propagated toward the rear free surface. When it reachen the rear free surface, the shock wave is reflected as a rarefaction wave that imparts an additional particle velocity to the material and; herice, to the gage. The additional increment in particle velocity imparted by this rareigction is in the ame direction as the increment iraparted by the chock wave, although the rarefaction is propagating in the opporite direction. At point $D$ in Figure 1, the rarefaction arrive at the gage and accelerates it to velocity $E$. If the portion of the record $B C$ is essentivily the ame from gage to gage in a given material, the shock wave is considered to be a steady wave. In this case, the time duration between points $B$ or $C$ (or any corresponding points in between) on any two gage records, together with the distance between those gages, may be used to compute a shock velocity. This shock velocity, together with the particle velocity given by the plateau level $C D$, is sufficient to calculate a point on the Hugoniot curve for the material. If the material is dispersive under shock loading, as it might be if the shock velocity is strain-rate sensitive or the material exhibits dynamic yielding, pore collapse, or phase transitions, a steady state wave will not develop. In such cases, the particle velocity rise from points B to $C$ will have a more complex structure and will vary from gage to gage. The portion of the profile from 
point $D$ to $E$, which represents a relief of the stress in the material by the rarefaction wave, is generally unsteady and flattens out with propagation distance in all materials in which the sound speed decreases with decreasing stress. However, even if the shock wave and the rarefaction wave are both unsteady, a set of particle velocity-time profiles from a single experiment can be used to deduce certain properties of the stress-strain behavior of materials under dynamic loading conditions. For example, the first arrival of the rarefaction, point $D_{0}$ can be compared for two or more gages, and used to salculate the longitudinal sound speed, $C_{l}$, in the compressed state.

The data from each of the experiments were recorded on Polaroid film as voltage-time histories. These records were digitized and then converted from voltage-time histories to particle velocity-time histories using Eq. (1). The conversion of these particle velocity-time history records to equation-ofstate data requires expressions relating particle velocity history to the material properties of interest (i.e., stress and specific volume). These expressions can be derived by using the conservation equations for uniaxial flow. ${ }^{3}$ The equations for conservation of mass and linear momentum are

$$
\begin{aligned}
& \left(\frac{\partial p}{\partial t}\right)_{h}+\rho\left(\frac{\partial U_{P}}{\partial x}\right)_{t}=0 \\
& \rho\left(\frac{\partial U_{p}}{\partial t}\right)_{h}+\left(\frac{\partial \sigma}{\partial x}\right)_{t}=0
\end{aligned}
$$

where $\rho$ is the density, $\sigma$ the axial stress, $x$ the Eulerian space coordinate, $h$ the Lagrangian space coordinate, and the time. In our experiments, particle velocities were measured at a consiant Lagrangian coo:dinate. Therefore, using the relationship

$$
\left(\frac{\partial h}{\partial x}\right)_{t}=\rho / \rho_{0}
$$

for uniaxipd flow, and the identities

$$
\mathrm{C}_{\mathrm{v}}\left(\frac{\partial \mathrm{t}}{\partial \mathrm{U}_{\mathrm{p}}}\right)_{\mathrm{h}}\left(\frac{\partial \mathrm{U}_{\mathrm{p}}}{\partial \mathrm{h}}\right)_{\mathrm{t}} \equiv \mathrm{C}_{\mathrm{\sigma}}\left(\frac{\partial \mathrm{t}}{\partial \sigma}\right)_{\mathrm{h}}\left(\frac{\partial \sigma}{\partial \mathrm{h}}\right)_{\mathrm{t}} \equiv-1
$$

where

$$
\mathrm{C}_{\mathrm{U}_{\mathrm{p}}}=\left(\frac{\partial \mathrm{h}}{\partial \mathrm{t}}\right)_{\mathrm{U}_{\mathrm{p}}} \text { and } \mathrm{C}_{\mathrm{a}}=\left(\frac{\partial \mathrm{h}}{\partial \mathrm{t}}\right)_{\sigma} \text {, }
$$

Eqs. (4) and (3) can be rewritten as

$$
\begin{aligned}
& \left(\frac{\partial V}{\partial U_{p}}\right)_{h}=-\frac{V_{0}}{C_{U_{p}}} \\
& \left(\frac{\partial o}{\partial U_{p}}\right)_{h}=\rho_{0} C_{o}
\end{aligned}
$$

where $\mathrm{V}=1 / \rho$ is the specific volume

In the case of a steady wave (i.e., $C_{U_{p}}=C_{\sigma}=a$ constant, where the constant is $U_{3}$, the shock velocity), integration of Eqs. (5) and (6) yields the jump conditions

$$
\begin{aligned}
& \mathrm{V}=\mathrm{V}_{\mathrm{0}}\left(1-\frac{\mathrm{U}_{\mathrm{p}}}{\mathrm{U}_{\mathrm{s}}}\right) \\
& \sigma=\rho_{0} \mathrm{U}_{\mathrm{p}} \mathrm{U}_{\mathrm{s}} .
\end{aligned}
$$

Equations (7) and (8) were used in the analysis of the shock state in several of our experiments, i.e., whenever steady loading conditions prevailed, to obtain stress and specific volume from measured shock and particle velocities. In the analysis of the remaining data, it was assumed that the nonsteady flow was that of simple waves. In the case of nonsteady simple waves, the phase velocities at constant stress and particle velocity, $\mathrm{C}_{\sigma}$ and $\mathrm{C}_{\mathrm{U}_{\mathrm{p}}}$ respectively, are equal but are functions of particle velocity rather than constants. In this case, the digitized particle velocity-time data from the experiments can be used to compute $\mathrm{C}_{\sigma}$ and $\mathrm{C}_{\mathrm{U}_{\mathrm{p}}}$; then numerical integration of Eqs. (5) and (6) can be used to obtain the relationship between stress and specific volume throughout the nonsteady wave. This integration was accomplished with a computer code called GANDALF, which is our interactive version of the Stanford Research Institute Lagrange Gage code (see Ref. 4). 


\section{EXPERIMIENTAL RESULTS}

In this section we have presented the experimentil results in tabular and graphical form and have highlighted seatures of the data which are significant. The format in which the data and results are presented is similar for each geologic material. This format consists of the following:

1. Tabulated data - Entries in the tables refer to the Hugoniot state behind the shock. The quantity $\mu$ $=\rho / \rho_{0}-1$ is the compression, and the quantity $C_{L}$ is the longitudinal sound speed in the compressed material behind the shock.

2. Particle velosity-time profiles - Curves are examples of Lagrangian particle velucity-time histories as recorded by the gages on a single test. They are presented on a common time base and exhibit the obscryed characteristics of the various materials.

3. Compression curves - Curves show the Hugoniot points and, in some cases, the loading and unloading paths followed by the material in normal stress $(\sigma)$-compression $(\mu)$ space. Quasi-static compression data or hydrostatic pressure-compression data and, in some cases, quasi-static uniaxial straín. data are included for comparison.

4. Shock velocity vs particle velocity plots Hugoniot curves in which the shock velocity vs the particle velocity is plotted. Abrupt changes in slope or deviations from linear behavior of these curves are indicators of the occurrence of such phenomena as phase changes, failure phenomena, or irreversible pore collapse.
5. Sound speed vs density $\rightarrow$ Plots of the longitudinal sound speed behind the shock vs the density behind the shock. The value of the sound speed at ambient dersity is taken from ultrasonic data as referenced.

\section{Wisterly Granite}

Westerly granite was obtained from Bonner Monument Company of Westerly, Rhode Island. It was the blue variety with an average density of 2.65 $\mathrm{Mg} / \mathrm{m}^{3}$ and a porosity of approximately $1 \%$.

Thirteen experiments ware conducted using Westerly granite, and the resuits are presented in Table 2. In several of the experiments, the impacting projectile head was PMMA; in the remainder, those in which the particle velocity is half the projectile velocity, the impactor was granite. Figure $4 a$ is a particle velocity-time history characteristic of this material. These data show no evidence of a precursor, but in some particle velocity histories, evidence of a slight precursor was observed by Swift ${ }^{5}$ and Larson ${ }^{6}$ in the vicinity of 2.5-3.0 GPa. Rosenberg ${ }^{7}$ also reported a precursor under plane wave loading conditions in relatively thick samples of dry granite recorded by stress gages. This precursor has never been observed to bo well developed and separated from the main wave; it shows little deviation from

Table 2 Hupoitot data lor dy Weatity maile.

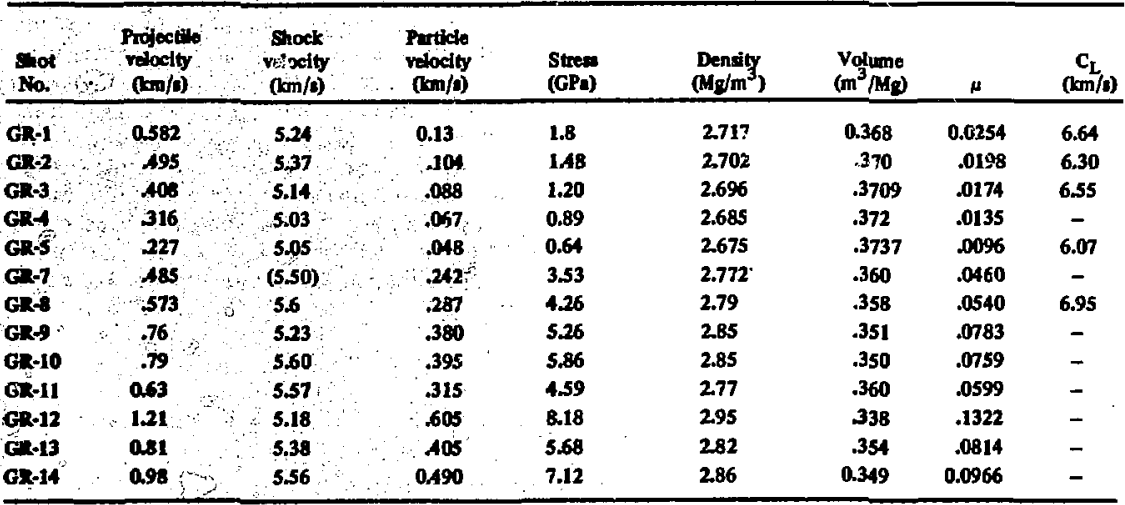



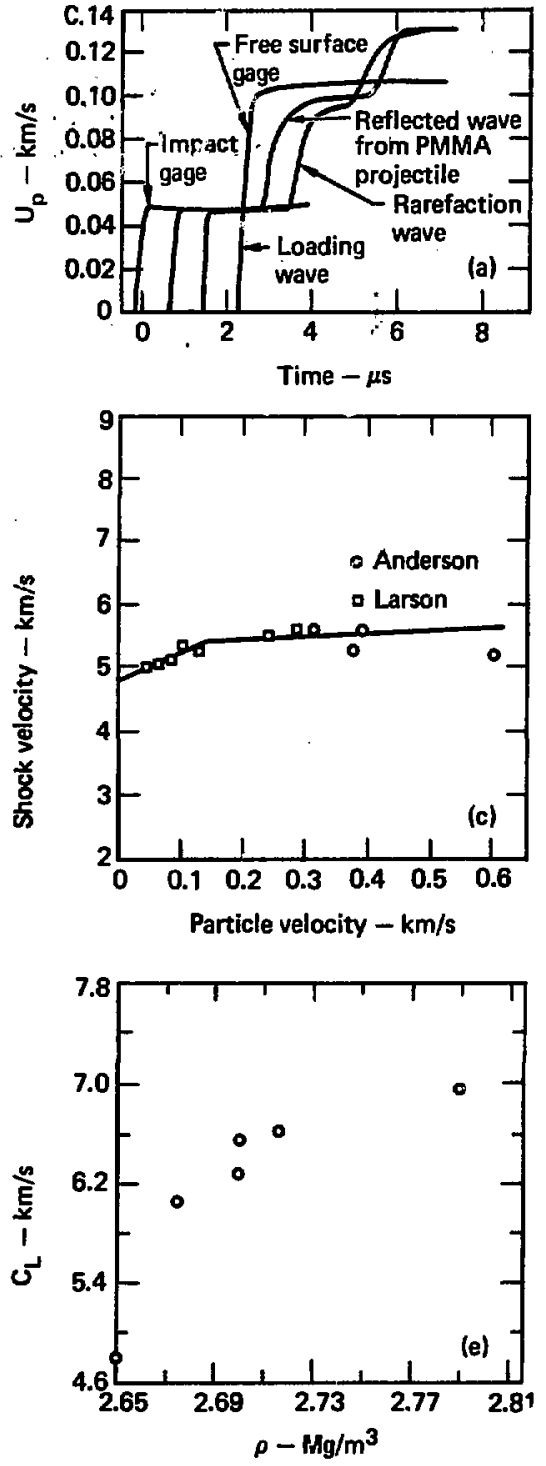
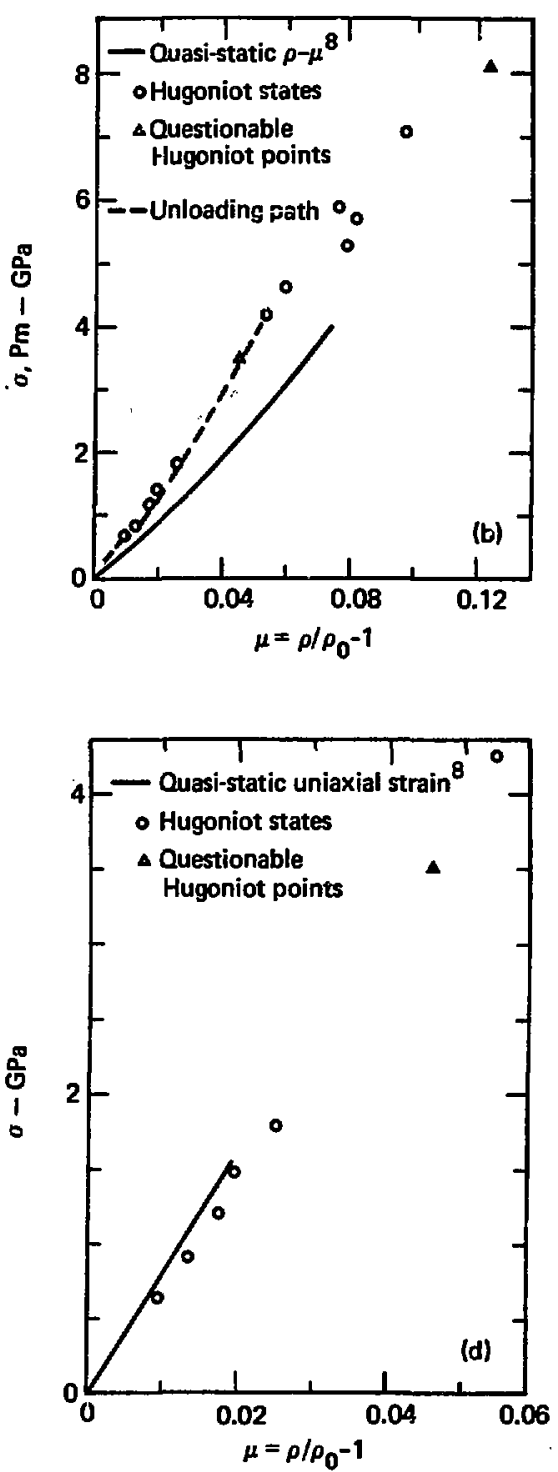

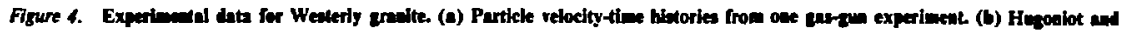

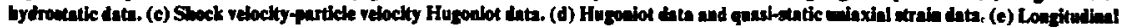
sond speed a density. 
steady wave befiavior. Consequently, our data indicates that loading and unloading in the stresscompression $(\sigma-\mu)$ plane occurs essentially along a straight line, as shown lis Fig. 4b. However, the plot of shock velocity vs pa.tinle velonity (Fig. 4c) exhibits a shange in slope between the lower and higher stress data. With the two straight-line segments drawn as they are in Fig. 4c, the discontinuity in slope occurs at a stress of approximately $2.0 \mathrm{GPa}$. This change in slope implies that, when it reaches stresses of approximately $2.0 \mathrm{GPa}$, the material begins to change in volume with the increasirig stress more than it would have if the Huganjot had continued along the initial straight line. Inasmuch as no phase transitions, resulting in a decrense in volume, are known to occur in granite in this stress region, we believe that this change in slope may be associated with pore collapse. Although no evidence of volume decrease attributable to pore collapse bas been observed by Heard et al. ${ }^{8}$ in the hydrostatic experiments up to stress levc's of $\mathbf{4 . 0}$ $\mathrm{GPa}$, shear stresses which enhance pore collapse may exist in the one-dimensional shock wave experiments, but are not present in the hydrostatic experiments. The stress level of $2.0 \mathrm{GPa}$ is not grossly inconsistent with the 2.5-3.0 GPa level of the slight precursor. Furthermore, since Westerly granite has only $1 \%$ porosity, one third of which is associated with microcracks (see Ref. 9) which close at hundredths to tenths of a GPa and the remaining two thinds is associated with more nearly spherical pores which could close at much higher stresses, a large volume hysteresis upon loading and unloading would not be expected."

Figure 4d compares dynamic and quasi-static uniaxial strain data to a stress of approximately 1.5 GPa. The agreement is quite good. Figure 4e pluts longitudinal sound speeds for Westerly granite. The value of $4.8 \mathrm{~km} / \mathrm{s}$ at a density of 2.65 $\mathrm{Mg} / \mathrm{m}^{3}$ was measured ultrasonically by Heard et al. and the other yalues were determined from the current shock wave experiments. The rapid initial increace in velocity with density is consistent with the closing of microcracks.

\section{Nugget Sandstone}

The nugget sandstone was obtained from the Parley's Canyon area near Salt Lake City, Utah.

\footnotetext{
-In this paper porosity in the form of relatively long-flat cracks which cen be closed by streases of the order of $0.1-0.2 \mathrm{GPa}$ is eallod mierocruck ponosity, while porosity that is more nearly opherion in is ipe and requires stresces of 1-10 GPa or more to clowe is calle l pore porotity.
}

The material was the red variety, which contains nominally $90 \%$ quartz. The initial tests, the MF series, used material with an average bulk density of $2.55 \mathrm{Mg} / \mathrm{m}^{3}$ and a corresponding dry porosity of about $4 \%$. The zecond series of tests was conducted on samples with bulk densities between 2.42 and $2.51 \mathrm{Mg} / \mathrm{m}^{3}$. The corresponding range of dry porosity in these samples is 6-9\%.

Table 3 records the results from 13 successful shock wave experiments in nugget sandstone loaded perpendicular to the bedding plane. Typical particle velocity-time histories for one of these experiments are shown in Fig. 5a. In this experiment, the nugget sandstone target was impacted with a PMMA projectile. The initial jump in particle velocity is due to the shock wave; it is followed by a second wave resulting from the rarefaction propagating back from the free surface tow'ard the impact surface. Upon reaching the impact surface, the PMMA interface, this rarefaction is reflected as a secc nd shock, back through the sandstone toward the free surface, where it is again reflected as a rarefaction. Thus, in Fig, 5a, the shock-reflected rarefaction process occurs twice, generating four steps in particle velocity.

In all the experiments on nugget sandstone, the loading waves were steady, and the resulting Hugoniot data shown in Fig. 5b suggests quasielastic behavior. However, unloading curves in this stress dompression $(\sigma-\mu)$ plane showed a slight amount of irreversible volume loss at low stresses ( $\sigma$ $<$ I.5 GPa). This slight amount of compaction is assumed to be associated with the closure of thin microcracks at very low stresses. Upon release from higher stre-s-shocked states ( $\sigma>5.0 \mathrm{GPa}$ ), the unloading curves imply an irreversible loss in specific volume, which is approximately equal to the porosity initially present in the material.

A piot of shock velocity vs particle velocity, shown in Fig. 5c, exhibits a change in slope in the vicinity of $1.5 \mathrm{GPa}$. This phenomenon is associated with the softening of a material that would occur if pores would begin to crllapse. These data suggest that the nugget sandstone matrix behaves essentially elastic up to approximately $1.5 \mathrm{GPa}$, with the exception of a small loss of porosity associated with microcrack closure at very low stress. They further suggest that, at approximately $1.5 \mathrm{GPa}$, the porous matrix begins to crush, and most of the porosity is eliminated by stresses in excess of $5.0 \mathrm{GPa}$.

Figure 5d compares dynamic and quasi-static uniaxial strain data to stresses of approximately 2.2 GPa. The agreement is quite good, suggesting little time-dependent behavior in nugget sandstone, at least up to $2.2 \mathrm{GPu}$. The longitudinal sound 

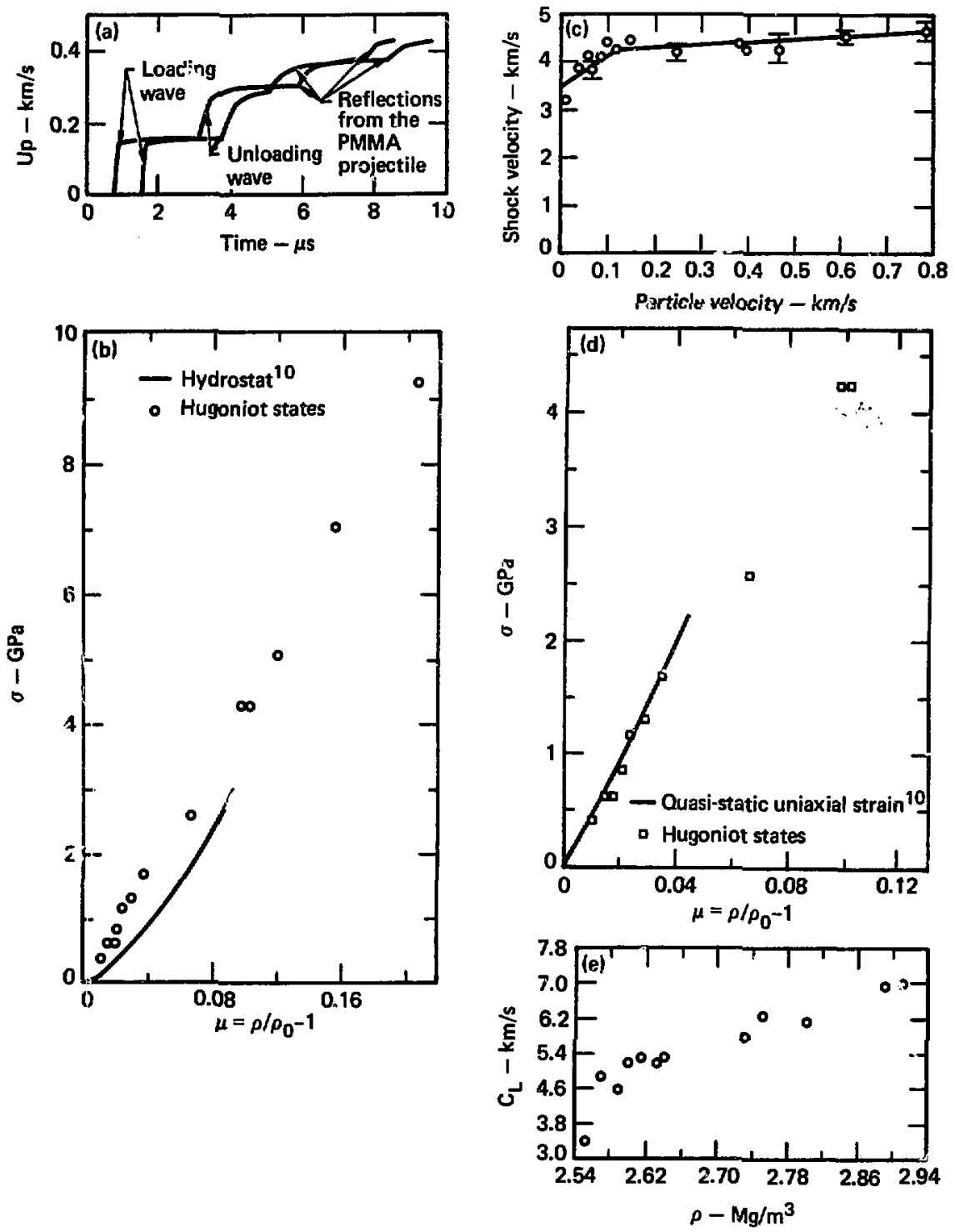

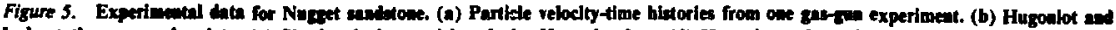

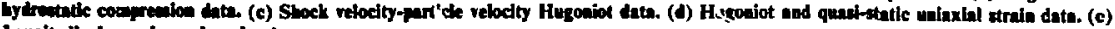

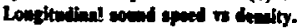


Table 3. Hugoniot dats for dry numget sindatone.

\begin{tabular}{|c|c|c|c|c|c|c|c|c|c|}
\hline $\begin{array}{l}\text { Shot } \\
\text { No. }\end{array}$ & 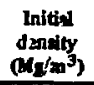 & $\begin{array}{l}\text { Profectise } \\
\text { relocity } \\
(\mathrm{km} / \mathrm{b})\end{array}$ & $\begin{array}{l}\text { Shock } \\
\text { rolocity } \\
(\operatorname{lon} / s)\end{array}$ & & $\begin{array}{l}\text { Particle } \\
\text { velocily } \\
\text { (km/s? }\end{array}$ & $\begin{array}{l}\text { Stre: } \\
\text { (GPa) }\end{array}$ & $\begin{array}{c}\text { Density } \\
\mathrm{afg}^{3} \mathrm{~m}^{3} \text { ) }\end{array}$ & $\mu$ & $\begin{array}{l}\text { Sound } \\
\text { speed } \\
(\mathrm{mm} / \mathrm{s})\end{array}$ \\
\hline MP-5s & 2.55 & 0.227 & 4.11 & & 0.0611 & 0.64 & 2.59 & 0.0152 & 4.55 \\
\hline MF-56 & 2.55 & .141 & 3.86 & & $.039 \%$ & 0.391 & 2.57 & .0104 & 4.86 \\
\hline MF-S1 & 2.551 & .586 & 4.42 & . & .150 & 1.65 & 2.64 & .0353 & 5.3 \\
\hline MF-52 & 2.58 & A8s & 4.28 & . & .120 & 1.31 & 2.633 & .0285 & 5.2 \\
\hline MP-5S & 2.55 & 402 & 4.43 & & .103 & 1.17 & 2.614 & .0235 & 5.28 \\
\hline MPS4 & 2.55 & .321 & 4.10 & & .0824 & 0.86 & 2.599 & .0204 & 5.14 \\
\hline DRN1U-1 & 2499 & .795 & 4.30 & & .397 & 4.27 & 2.75 & .101 & 6.25 \\
\hline DRNU-2 & 2490 & 0.98 & 4.30 & & A70 & 5.05 & 2.80 & .120 & 6.11 \\
\hline DRNU-3 & 2507 & 1.23 & 4,48 & & .615 & 7.02 & 2.89 & .156 & 6.93 \\
\hline DRNu 6 & - & 1.58 & 4.67 & & .79 & 9.23 & 3.01 & .204 & 6.97 \\
\hline DRNU.7 & - & 0.78 & 4.39 & & .39 & 4.26 & 2.73 & .097 & 5.78 \\
\hline DRNU-10 & 2422 & .138 & 3.85 & & .069 & 0.645 & 2.47 & .0182 & - \\
\hline DRNU-12 & - & 0.51 & 4.19 & & 0.255 & 2.58 & 2.58 & 0.0648 & - \\
\hline
\end{tabular}

speeds measured in the various shock wave experiments are shown in Fig. 5e. The measurement at a density of $2.55 \mathrm{Mg} / \mathrm{m}^{3}$ was determined ultrasonically by Shock et al. ${ }^{10}$ As with Westerly granite, the rapid initial increase in velocity with a comparable increase in density is consistent with the closing of microcracks.

\section{Blair Dolomite}

The Blair dolomite was obtained from the Berkeley Company in Martinsburg, West Virginia. The measured bulk density of this fine-grained rock, which is more than $98 \% \mathrm{CaMg}\left(\mathrm{CO}_{3}\right)_{2}$, was $2.84 \mathrm{Mg} / \mathrm{m}^{3}$ and the porosity was approximately $1 \%$.

Table 4 tabulates the results for all six shock wave experiments in Blair dolomite, and Figure 6a shows the particle velocity-time histories for the two internal gages in experiment MF-25. In the six experiments, the loading wave was composed of two parts: (1) a fast rising, steady part whose amplitude was dependent upon stress, and (2) a more slowly rising nonsteady part that brought the sample to its final loading state. These observations disagree with those made by Grady et al, 11,12 who report profiles of similar shape but claim that, for loading states below $2.5 \mathrm{GPa}$, the waves are steady and only increments above $2.5 \mathrm{GPa}$ show nonsteady characteristics. We currently have no explanation for this difference in behavior, but our observations are consistent with similar nonsteady behavior observed by Larson ${ }^{6}$ in shock wave experiments that employed spherical divergent flow. In the latter experiments, a spherical high explosive charge was used to load the dolomite, and particle velocity gages measured particle velocity-time histories at

Toble 4. Heraiot dati for But dolomite.

\begin{tabular}{|c|c|c|c|c|c|c|c|c|}
\hline $\begin{array}{l}\text { Sol } \\
\text { Ha. }\end{array}$ & 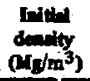 & $\begin{array}{l}\text { Projoctilo } \\
\text { velocity } \\
\text { (kmom/a) }\end{array}$ & $\begin{array}{l}\text { Shock } \\
\text { velocity } \\
(\mathrm{km} / \mathrm{s})\end{array}$ & $\begin{array}{l}\text { Perticle } \\
\text { velocity } \\
(\mathrm{km} / \mathrm{s})\end{array}$ & $\begin{array}{l}\text { Stress } \\
\text { (CPA) }\end{array}$ & $\begin{array}{l}\text { Density } \\
\left(\mathrm{Mg}^{3} \mathrm{~m}^{3}\right)\end{array}$ & $\mu$ & $\begin{array}{l}\text { Se nd } \\
c_{\text {F }} \text { d } \\
\text { (an. }\end{array}$ \\
\hline $\mathbf{M P}-65$ & 284 & 0.05 & 5.30 & 0.017 & 0.24 & 2.848 & 0.00288 & 6.00 \\
\hline MF-58 & 284 & 0.153 & 5.92 & .030 & 0.44 & 2.852 & .00431 & 7.34 \\
\hline IRT-57 & 284 & -0.20 & 6.12 & .040 & 0.63 & 2.856 & .00575 & 7.68 \\
\hline MT-26 & 284 & 0.200 & $6 A \mathrm{~L}$ & .100 & 1.70 & 2.885 & .0159 & 6.95 \\
\hline MF-25 & 284 & 0.392 & 6.69 & .196 & 3,40 & 2.929 & .0314 & 7.33 \\
\hline MF-37 & 284 & 0.584 & 6.62 & 0.290 & 5.33 & 2.974 & 0.0470 & 7.92 \\
\hline
\end{tabular}



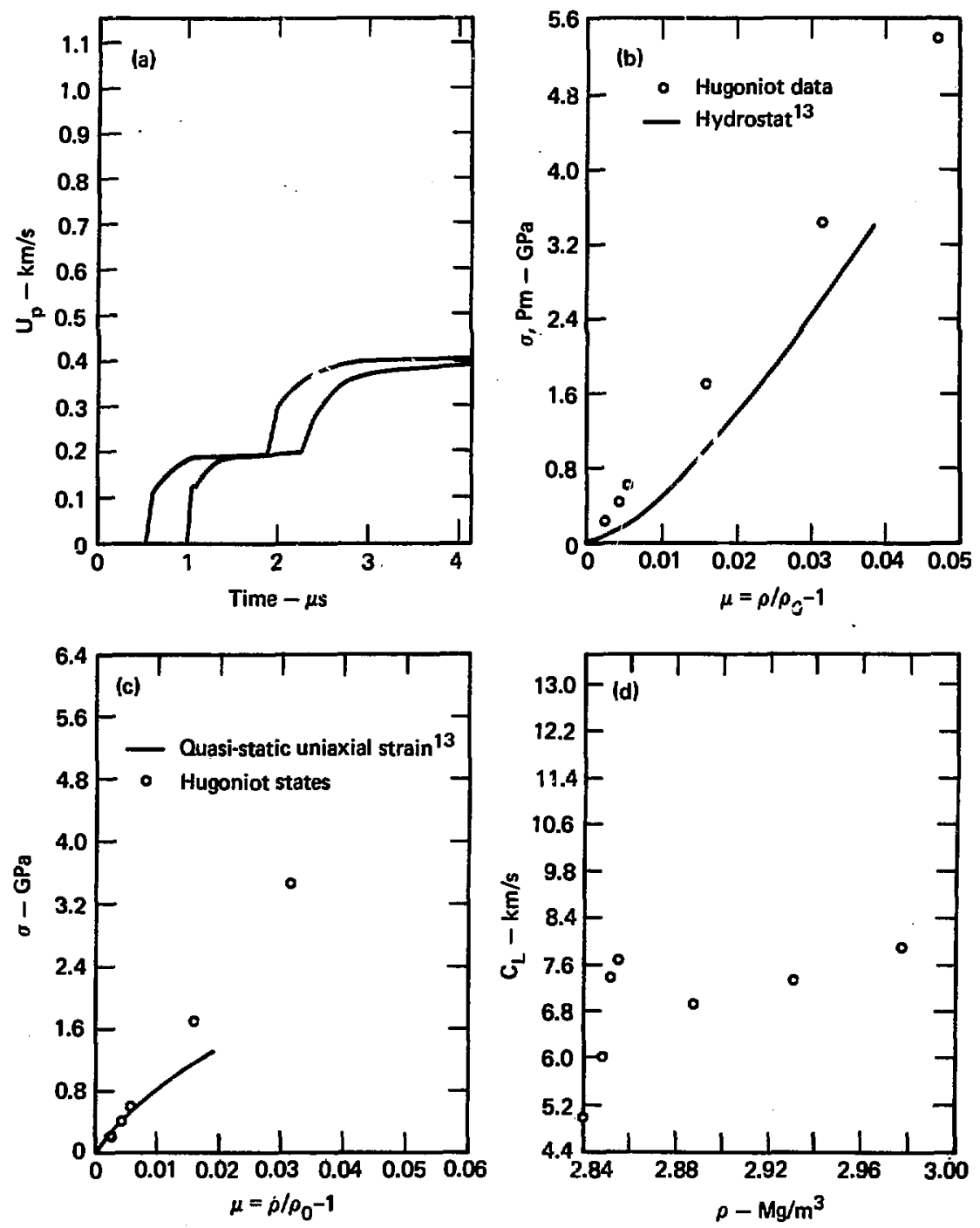

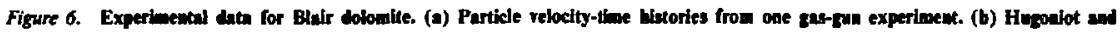

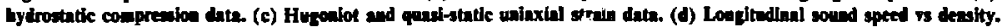


various radial distances from the source. In these experiments, nonsteady flow was observed at stresses as low as $0.4 \mathrm{GPa}$. Figure $6 \mathrm{~b}$ compares Hugoniot and hydrostatic compression data observed by Heard et;al. 13

In Figure $6 c$, a comparison of dynamic and quasistatic uniaxial strain data shows a divergence above a stress of approximately $0.4 \mathrm{GPa}$. The reason for this divergence is unknown. Longitudinal sound speeds determined from the shock wave experiments are shown graphically in Fig. 6d.

\section{Polycrystalline Sodium Chloride ( $\mathrm{NaCl})$}

The polycrystalline $\mathrm{NaCl}$ samples were taken from Leslie Mill feed salt of $99.4-99.9 \%$ purity. The fine-grained salt was pressed isostatically for 1 hour at $120^{\circ} \mathrm{C}$ using $0.136 \mathrm{GPa}$ pressure to produce the large cylinders (approximately $0.36 \mathrm{~m}$ diam and $0.36 \mathrm{~m}$ long) from which the samples were taken. The measured bulk density of this material was $2.13 \mathrm{Mg} / \mathrm{m}^{3}$, indicatings a porosity of $1.6 \%$.

Table 5 lists the Hugoniot data obtained from the three experiments in which this material was used, and Fig. 7a shows the particle velocity-time histories recorded in one experiment. In Fig. 7a, the first gage shows the input wave that developed at the interface between the $\mathrm{NaCl}$ and the PMMA projectile insert. The second, third, and fourth gages in this figure clearly show the development of a precursor wave in the $\mathrm{NaCl}$, which we attribute to dynamic yielding of the $\mathrm{NaCl}$ matrix. Both precursor wave and the wave profile immediately following it are nonsteady. We attribute this to rate effects associated with the collapse of microcracks and pores. Loading and unloading paths, calculated using Eqs. (5) and (6), are shown in Fig. $7 b$ with a quasi-static compression curve (see Ref, 14). The unloading paths, represented by the dashed lines, show considerable hysteresis and converge towards crystal density, indicated by $\mu_{c}$ on the abscissa of the graph. This suggests that all, or nearly all, porosity has been eliminated at a stress of I $\mathbf{G P a}$. The offset of the Hugoniot states ahove the hydrostat (0.1-0.15 $\mathrm{GPa}$ ) suggests that rate effects are causing different effective moduli for these extremes of strain rate.

A comparison of the dynamic and quasi-static uniaxial strain results, shown in Fig. 7c, suggests reasonable agreement for an extrapolation of the quasi-static data. Longitudinal sound speed from the shock wave experiments are shown graphically in Fig. 7d.

\section{Dry Mt. Helen Tuff}

Mt. Helen tuff was obtained from a site near $M t$. Helen, southeast of Tonapah in Nye County, Nevada. It is a fine-grained rock with a porosity of about $40 \%$ and a dry density of $1.46 \mathrm{Mg} / \mathrm{m}^{3}$.

Hugoniot data are presented in Table 6. A typical series of particle velocity-time histories for a single experiment is shown in Fig. 8a. The first gage is located on the impact surface and shows the particle velocity imparted to the target material. Subsequent gages show the development of the wave profile, including the rarefaction from the free surface. The precursor wave shown in Fig. 8a is dispersive, with the front traveling at or near longitudinal sound speed $(2.5 \mathrm{~km} / \mathrm{s})$. The formation of this wave, which has an amplitude of approximately $0.25 \mathrm{GPa}$, is attributed to dynamic failure of the rock matrix; its dispersion is probably associated with the closing of microcracks and other grain boundary effects. The second or main loading wave is traveling at a speed of approximately $1.5 \mathrm{~km} / \mathrm{s}$. We attribute the highly dispersive nature of this second wave to rate effects associated with the collapse of the pores present in this extremely porous material.

Figures $8 \mathrm{~b}$ and $8 \mathrm{c}$ show Hugoniot states and unloading paths computed from the data using Eqs. (5) and (6). The figures also show a quasistatically measured hydrostat of Heard et al. ${ }^{15}$ The unloading data from the shock wave experiments show that much, if not all, of the porosity has been

Table 5. Fuponiot date for poiyerystalline sodium chloride.

\begin{tabular}{|c|c|c|c|c|c|c|c|c|c|c|}
\hline $\begin{array}{l}\text { Shot } \\
\text { Na }\end{array}$ & $\begin{array}{l}\text { Initiol } \\
\text { dendity } \\
\text { (M/mis) }\end{array}$ & $\begin{array}{l}\text { Projectilo } \\
\text { velocity } \\
(\mathrm{mm} / \mathrm{h})\end{array}$ & $\begin{array}{l}\text { Procurnor } \\
\text { wiocity } \\
(\mathrm{km} / \mathrm{s})\end{array}$ & $\begin{array}{l}\text { Suock } \\
\text { wave } \\
\text { velocity } \\
(\mathrm{mm} / \mathrm{b})\end{array}$ & $\begin{array}{c}\text { Perticle } \\
\text { velocity } \\
(\mathrm{km} / \mathrm{s})\end{array}$ & $\begin{array}{l}\text { Precurpor } \\
\text { stre: } \\
\text { (GP) }\end{array}$ & $\begin{array}{l}\text { Shodk } \\
\text { wave } \\
\text { stress } \\
\text { (GPa) }\end{array}$ & $\begin{array}{l}\text { Dendity } \\
\left(\mathrm{M} / \mathrm{m}^{3}\right)\end{array}$ & $\mu$ & $\begin{array}{l}\text { Sound } \\
\text { speed } \\
(\mathrm{km} / \mathrm{s})\end{array}$ \\
\hline NN6 & 2.13 & 0406 & 4.28 & 3.31 & 0.138 & -0.08 & 0.986 & 2.218 & 0.0414 & 5.50 \\
\hline NN-7 & 2.13 & 594 & $4 A 2$ & 3.48 & 20 : & $\sim 0.12$ & 1.483 & 2258 & .0603 & 6.10 \\
\hline NN-8 & 2.13 & 0.491 & 4.30 & 3.38 & 0.170 & $\sim 0.12$ & 1.200 & 2.243 & 0.0531 & 6.00 \\
\hline
\end{tabular}



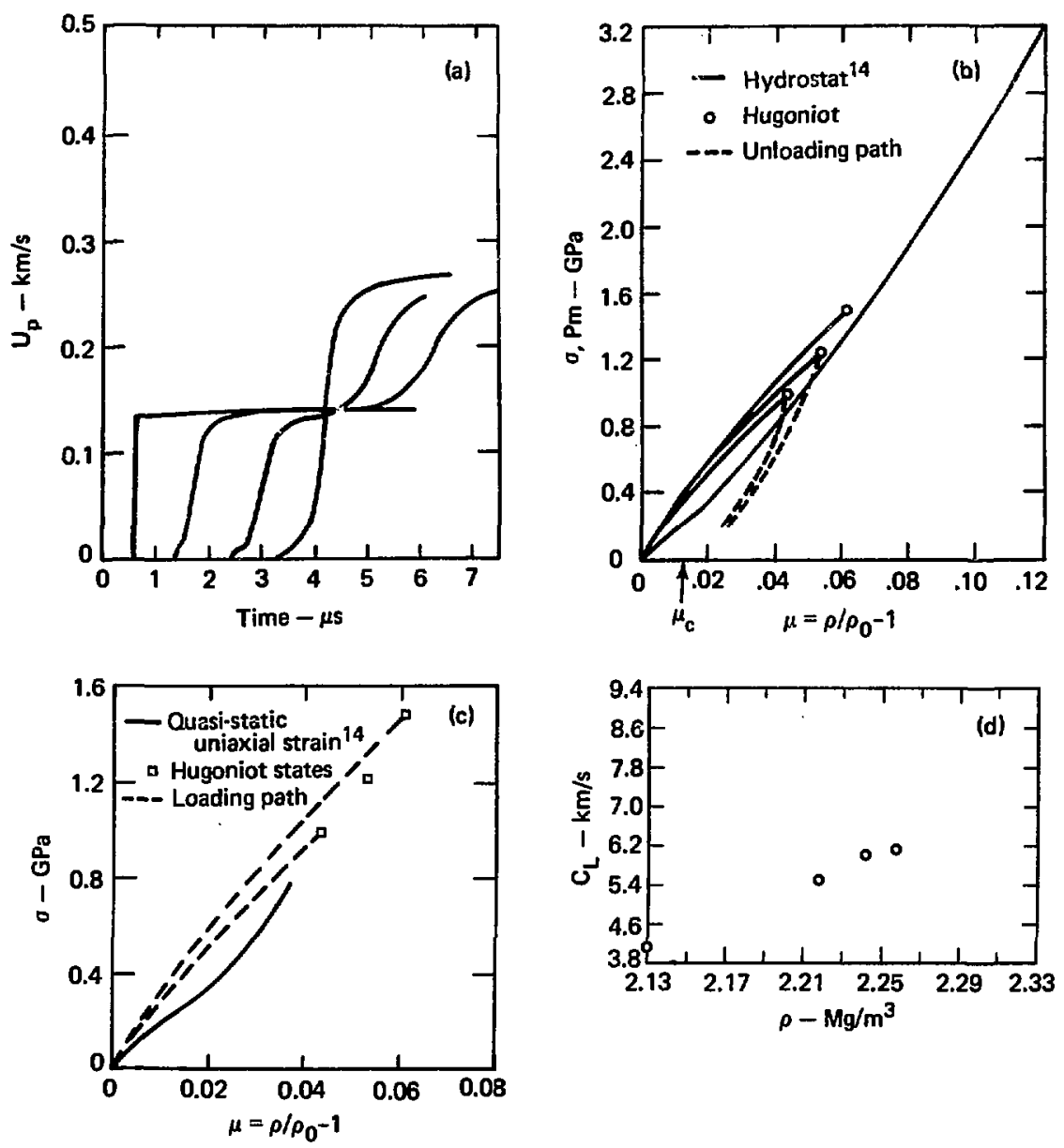

Figuse 7. Experineatal date for sodium chloride. (a) Partkle velocity-time histories from one gus-gun experiment. (b) Huigonlot and hydrostatic compression data. (c) Hugoniot and quasj-static uninxid strain data. (d) Longitudinal sound speed rs density.

eliminated at stresses of $3.0 \mathrm{GPa}$. The crossing and divergence of the hydrostatic and shock wave data are not completely understood but probably result from shear enhanced compaction." It is not completely clear why the crossover of the two sets of

-The enhanced compaction of porous materials in tests involving a shear component rather than the compaction resulting from a pure hydrostatic test. data did not occur at a stress much closer to the point of matrix failure. However, there is the possibility of competing time-dependent effects, such as an increase in strength with strain rate, which could act to "stiffen" the material. To complete the data display, Fig. 8c includes some high stress shock wave data obtained at Stanford Research Institute. ${ }^{16}$ 

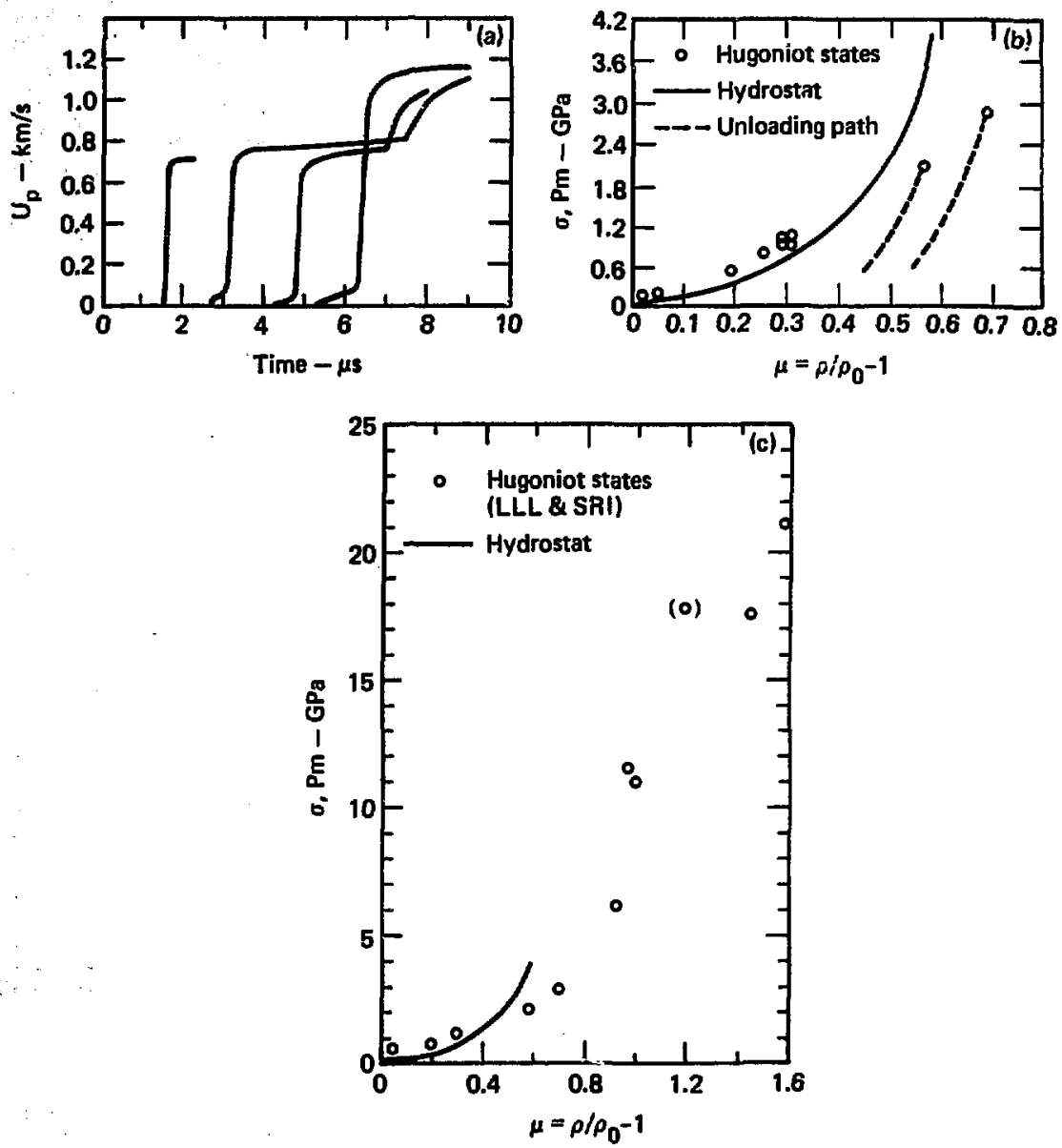

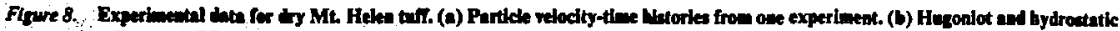

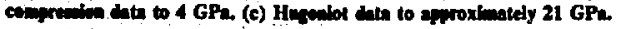

\section{Water-Saturated Mt. Helen Tuff}

Mt. Helen tuff was saturated by submerging samples in water and applying a partial vacuum until air bubbles no longer appeared on the sample surfaces. Measured saturated densities averaged $1.84 \mathrm{Mg} / \mathrm{m}^{3}$, indicating that an average of more than $95 \%$ of the pores were filled.
Hugoniot data and sound speeds determined from the various experiments are listed in Table 7. Figure 9a shows a particle velocity record from one experiment. The loading wave in Figure $9 \mathrm{a}$ is a single wave which appears to be very nearly steady. Only two experiments, MF-75 and MF-76, showed any sign of the development of a precursor wave. In these two experiments, the specimens were loaded 
Table 6. Hugoniot data for dry Mt Helen tuff.

\begin{tabular}{|c|c|c|c|c|c|c|c|c|}
\hline $\begin{array}{l}\text { Shot } \\
\text { No. }\end{array}$ & $\begin{array}{c}\text { Initial } \\
\text { density } \\
\left(\mathbf{M g}_{\mathrm{g}} \mathbf{m}^{3}\right)\end{array}$ & $\begin{array}{l}\text { Projectile } \\
\text { velocity } \\
\text { (km/s) }\end{array}$ & $\begin{array}{c}\text { Siock } \\
\text { velucity } \\
(\mathrm{km} / \mathrm{s})\end{array}$ & $\begin{array}{l}\text { Particle } \\
\text { velocity } \\
(\mathrm{km} / \mathrm{s})\end{array}$ & $\begin{array}{l}\text { Stress } \\
\text { (GPa) }\end{array}$ & $\begin{array}{l}\text { Density } \\
\left(\mathrm{Mg}_{\mathrm{g}} / \mathrm{m}^{3}\right)\end{array}$ & $\mu$ & $\begin{array}{l}\text { Sound } \\
\text { speed } \\
(\mathrm{km} / \mathrm{s})\end{array}$ \\
\hline MF-27 & 1.46 & 0.112 & 2.67 & 0.065 & 0.183 & 1.52 & 0.040 & 2.61 \\
\hline MF-24 & 1.46 & .144 & 2.50 & .087 & .220 & 1.54 & .054 & 2.74 \\
\hline$M F-23$ & 1.46 & .394 & 2.60 & .253 & .590 & 1.75 & .198 & - \\
\hline MF-34 & 1.46 & 492 & 2.49 & .319 & .765 & 1.84 & .260 & 206 \\
\hline MF-35 & 1.46 & .584 & 2.38 & .370 & .877 & 1.92 & .313 & 248 \\
\hline$M F-22$ & 1.46 & .558 & 2.67 & .366 & .887 & 1.90 & .299 & - \\
\hline MF-14 & 1.46 & .634 & 2.45 & .381 & .975 & 1.89 & .292 & 2.95 \\
\hline MF-20 & 1.46 & 0.634 & 2.48 & .398 & 0.995 & 1.92 & .315 & 2.17 \\
\hline DRTF4B & 1.46 & 1.227 & 2.44 & .72 & 2.05 & 2.289 & 568 & 3.56 \\
\hline DRTF5B & 1.4 & 1.497 & 2.23 & 0.91 & 2.96 & 2.467 & 0.689 & 3.13 \\
\hline
\end{tabular}

to the lowe stresses; we atribute the twowave structures a $c$ the closing of tine small amount of dry porosity ivat was still present in the sample. The absence of a precursor wave at higher stress is apparently the result of overdriving by the main wave, i.e., the main wave has a velocity greater than the precursor.

Figures $9 \mathrm{~b}$ and $9 \mathrm{c}$ show the Hugoniot points for all experiments. Figure $9 \mathrm{~b}$ also shows the unloading paths calculated using Eqs. (5) and (6). These paths how little, if any, evidence of hysteresis, suggesting that any porosity closed by compression is recovered as the material is unloaded. Figure 9c compares the Hugoniot data with the measured hydrostat. At the lower stresses, i.e., up to $1.2 \mathrm{GPa}$, the data are essentially superimposed, suggesting that the saturated rock has lost its strength, presumably as a result of a buildup of pore pressure. Beyond $1.2 \mathrm{GPa}$, the static and dynamic experimental data shown in Fig. 9c diverge. The hydrostat shows the volume compaction associated with the transformation of water to ice VI (at $1.2 \mathrm{GPa}$ ) and of ice VI to ice VII (at $2.4 \mathrm{GPa}$ ). However, the dynamic data give no indication of volume compaction. In fact, the shock wave data seem to suggest the formation of a metastable liquid phase in the high-pressure ice regimes. Such behavior of water under shock wave loading is not unexpected, as pure water shows the same characteristics. 17

Table 7. Hugoniot data for saturated Mt Helen tufr.

\begin{tabular}{|c|c|c|c|c|c|c|c|c|}
\hline $\begin{array}{l}\text { Shot } \\
\text { No. }\end{array}$ & $\begin{array}{l}\text { Initial } \\
\text { density } \\
\left(\mathbf{M g}^{3} \mathbf{m}^{3}\right)\end{array}$ & $\begin{array}{c}\text { Projectile } \\
\text { velocity } \\
(\mathbf{c m} / \mathrm{s})\end{array}$ & $\begin{array}{l}\text { Shock } \\
\text { velocity } \\
\text { (km/s) }\end{array}$ & $\begin{array}{l}\text { Purticle } \\
\text { velocity } \\
(\mathrm{mm} / \mathrm{s})\end{array}$ & $\begin{array}{l}\text { Streas } \\
\text { (GPa) }\end{array}$ & $\begin{array}{l}\text { Density } \\
\left(\mathbf{M g}^{\prime} / \mathrm{m}^{3}\right)\end{array}$ & $\boldsymbol{\mu}$ & $\begin{array}{l}\text { Sound } \\
\text { speed } \\
\text { (km/s) }\end{array}$ \\
\hline$M F-48$ & 1.84 & 0.588 & 2.64 & 0.271 & 1285 & 2.06 & 0.118 & 3.35 \\
\hline $\mathrm{MF}-63$ & 1.84 & .591 & 2.52 & .266 & 1.21 & 2.06 & .120 & 3.48 \\
\hline MF 62 & 1.84 & .490 & 2.42 & .220 & 1.00 & 2.03 & .101 & 2.96 \\
\hline MF-61 & 1.84 & .412 & 2.32 & .194 & 0.81 & 2.01 & .093 & 2.75 \\
\hline MF-59 & 1.84 & .312 & 2.16 & .162 & .62 & 100 & $\$ 23$ & 3.05 \\
\hline MF-60 & 1.84 & .217 & 1.94 & .115 & .44 & 1.95 & .058 & 2.94 \\
\hline MF-75 & - & .211 & - & .107 & .39 & 1.94 & .057 & - \\
\hline Precurror & 1.84 & - & 2.27 & .040 & .15 & - & .020 & \\
\hline MF-76 & - & .142 & - & .069 & 255 & 1.91 & .037 & - \\
\hline Precurtor & 1.84 & - & 1.80 & .042 & .147 & - & .020 & \\
\hline WTTF-1 & 1.83 & .65 & 2.57 & .295 & 1.387 & 2.07 & .129 & 3.43 \\
\hline WTTP-3 & 1.83 & .76 & 2.73 & .335 & 1.673 & 2.08 & .139 & 3.67 \\
\hline WTTP4 & 1.83 & .893 & 2.84 & .390 & 2.015 & 2.11 & .153 & $(3.30)$ \\
\hline WTTF-5 & 1.83 & 0.998 & 2.92 & .437 & 2.335 & 2.15 & .176 & 3.95 \\
\hline WTTF-6 & 1.83 & 1.16 & 3.09 & 0.488 & 2.82 & 2.16 & 0.135 & 3.83 \\
\hline
\end{tabular}



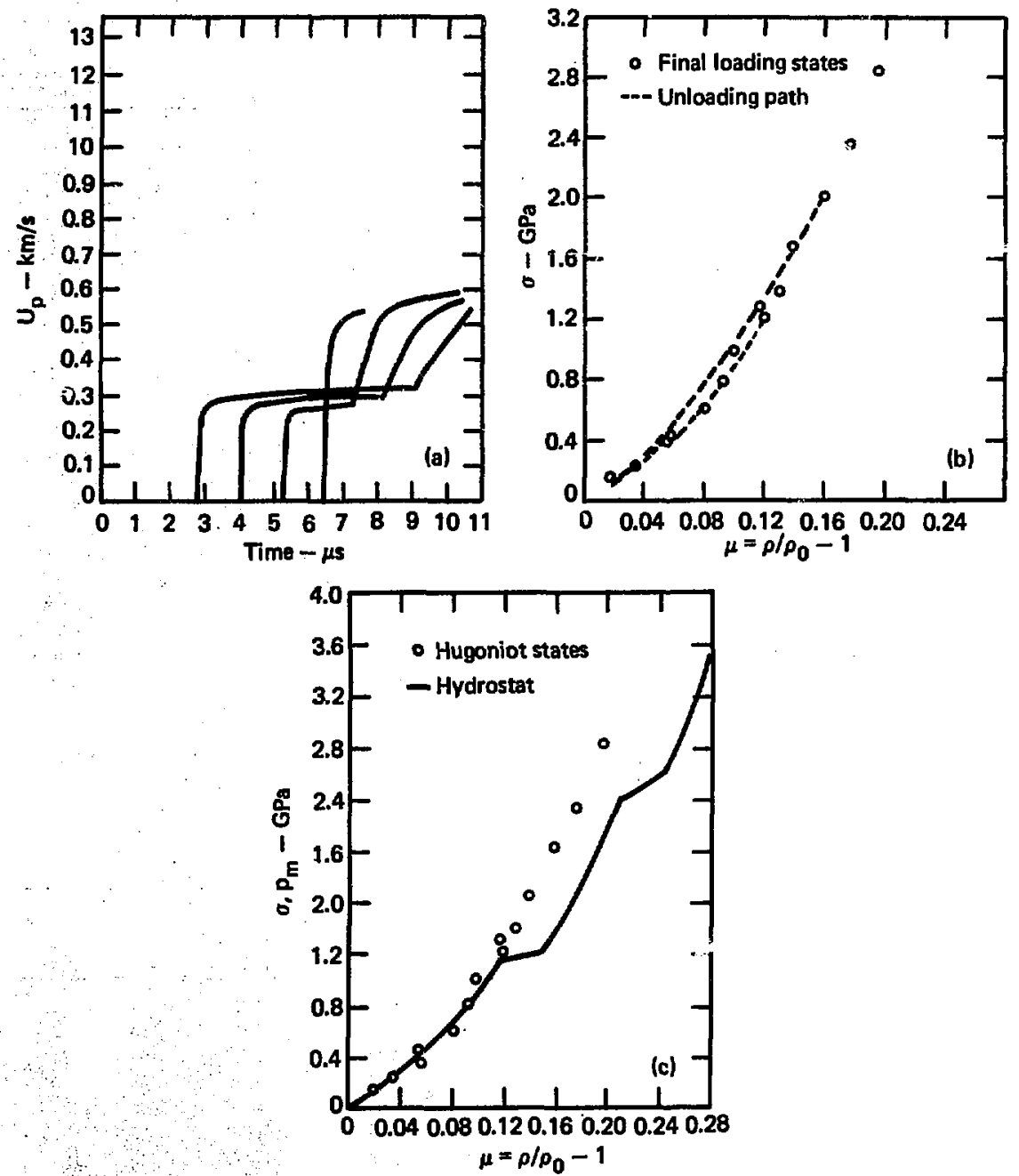

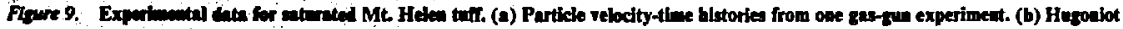

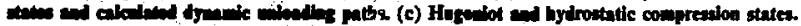




\section{Dry Indiana Limestone}

Indiana limestone, obtained from the Indiana Limestone Company quarry near Bedford, Indiana, is a calcite-cemented rock formed from shelis and shell fragments. The rock is more than $90 \%$ calcite $\left(\mathrm{CaCO}_{3}\right)$, and the samples had an average bulk density of $2.28 \mathrm{Mg} / \mathrm{m}^{3}$. The measured grain density was $2.70 \mathrm{Mg} / \mathrm{m}^{3}$, which gives an average porosity of $16 \%$.

Table 8 summarizes the data for all i0 experiments, and Fig. 10a shows the particle velocity-time histories for two internal gages in experiment DRLM-3. In this experiment, unloading originated at the projectile. The design of this experiment was similar to that shown in Fig. 1, except that a thin cylinder plate of dry Indiana limestone, backed by low density foam, was used as the projectile insert, and a relatively thick plate of dry Indiana limestone was used as the downstream plate in the target. This design was followed for the dry Indiana limestone experiment because of the large velocity difference between the first and second waves. Downstream unloading would have resulted in the unloading wave arriving at the interior gages before loading was completed. The records in Fig. 10a show the development of a precursor, which probably is due to matrix failure. Following the precursor, the main loading wave shows definite nonsteady behavior, which is attributed to the crushing of pores. As the rarefaction from the projectile arrives at the gages, the particle velocity is decreased towards zero.
Figures $10 b$ and $10 \mathrm{c}$ show the Hugoniot data for all 10 experiments, along with a measured hydrostat (see Ref. 18) and some high-stress shock wave data obtained at Stanford Research Institute. ${ }^{16}$ These comparisons show the shock wave data remainiug above the hydrostat at all stress levels. The apparent offset is about twice that expested from a combination of quasi-static strength and pressure compression data, but it is consistent with a $10 \%$ per decade inctease in strength with an increase in strain rate. However, this intcrpretation of the data implies the absence of any shear enhanced compaction, which is unlikely.

\section{Water-Saturated Indiana Limestone}

The Indiana limestone was saturated with water in the same manner as the Mt. Helen tuff. The samples selected for the tests had dry densities between 2.23 and $2.28 \mathrm{Mg} / \mathrm{m}^{3}$ and saturated densities between $2.4 \mathrm{i}$ and $2.48 \mathrm{Mg} / \mathrm{m}^{3}$. Six experiments were performed; data from these sppear in Table 9.

The four gage records obtained in experiment STLM-2 appear in Fig. Ita. The loading wave shows a definite spreading as it propagates. The reason for this nonsteady characteristic is unknown, but it may be the result of a small amount of unsaturated porosity or of phase transformation occurring in the calcite. Hugoniot and hydrostatic data are compared in Fig. $1 \mathrm{lb}$.

,

Table 8. Hugoniot data for dry Indiana Itmestone.

\begin{tabular}{|c|c|c|c|c|c|c|c|c|}
\hline \multirow[b]{2}{*}{$\begin{array}{l}\text { Shot } \\
\text { Na. }\end{array}$} & \multirow[b]{2}{*}{$\begin{array}{l}\text { Projectile } \\
\text { velocity } \\
\text { (km/s) }\end{array}$} & \multirow{2}{*}{ 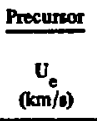 } & \multicolumn{6}{|c|}{ Shock wave } \\
\hline & & & $\underset{(\mathrm{km} / \mathrm{s})}{U_{\mathrm{s}}}$ & $\underset{(\mathrm{m} / \mathrm{s})}{\mathrm{U}_{\mathrm{p}}}$ & $\begin{array}{c}\sigma \\
(\mathbf{G P} \mathbf{z})\end{array}$ & $\mu$ & $\rho$ & $\begin{array}{l}\text { Sound } \\
\text { opeed } \\
\text { (tm/s) }\end{array}$ \\
\hline DRLM 4 & 0.218 & 4.68 & 2.78 & 0.079 & 0.538 & 0.024 & $2.34 S$ & 4.24 \\
\hline DRLM 5 & .319 & 4.55 & 2.28 & .122 & .711 & .050 & 2.405 & 4.44 \\
\hline DRLM 6 & .420 & 5.15 & 2.40 & .158 & .1002 & .068 & 2.445 & 3.12 \\
\hline DRLM 7 & .503 & 4.91 & 2.22 & .200 & .1151 & .088 & 2.492 & 3.61 \\
\hline DRLM 3 & 0.603 & 4.94 & 2.25 & 254 & 0.1478 & .112 & 2.546 & 4.10 \\
\hline DRLM IB & 1.21 & 4.62 & 2.70 & .52 & 3.28 & .230 & 2.804 & \\
\hline DRLM 2B & 1.46 & 4.33 & 2.88 & .64 & 4.25 & .275 & 2.908 & 5.00 \\
\hline DRLM 48 & 0.37 & 4.73 & 1.82 & .185 & 1.06 & .0942 & 2.49 & \\
\hline DRLM 5B & .802 & 4.59 & 2.43 & .401 & 2.46 & .200 & 2.73 & \\
\hline DRLY 68 & 0.95 & 4.89 & 2.42 & 0.475 & 2.87 & 0.227 & .82 & \\
\hline
\end{tabular}



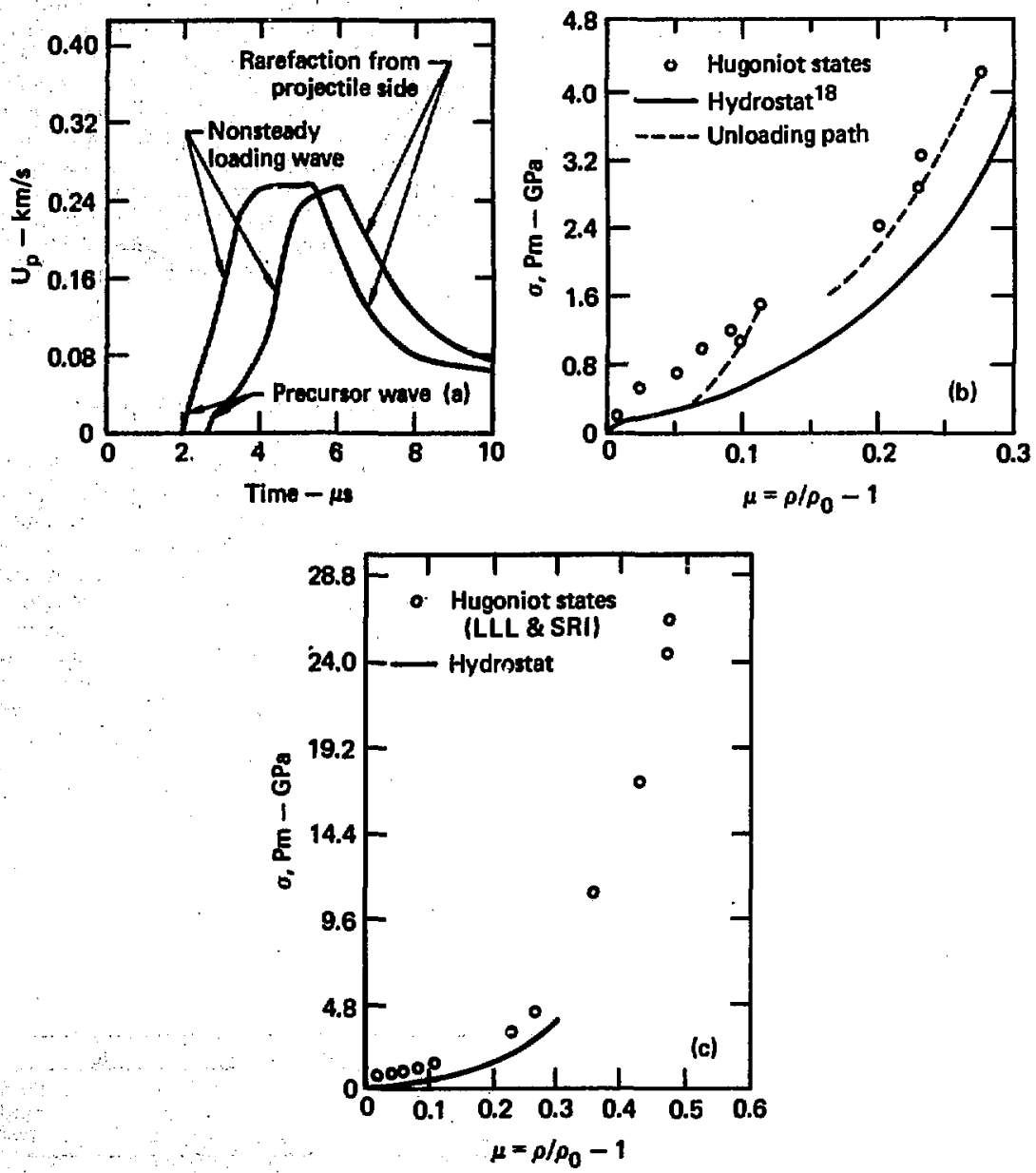

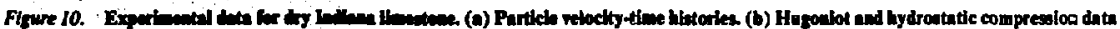

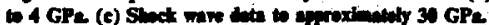


Table 9. Hugoniot data for saturated Indiana limestone.

\begin{tabular}{|c|c|c|c|c|c|c|c|}
\hline $\begin{array}{l}\text { Shot } \\
\text { No. }\end{array}$ & $\begin{array}{c}\text { Initiol } \\
\text { density } \\
\left(\mathbf{M} / \mathbf{m}^{3}\right)\end{array}$ & $\begin{array}{l}\text { Projectile } \\
\text { velocity } \\
\text { (km/s) }\end{array}$ & $\begin{array}{l}\text { Shock } \\
\text { velocity } \\
(\mathbf{k m} / \mathbf{s})\end{array}$ & $\begin{array}{l}\text { Particle } \\
\text { velocity } \\
(\mathbf{m} / \mathbf{s})\end{array}$ & $\begin{array}{l}\text { Stress } \\
\text { (GPa) }\end{array}$ & $\mu$ & $\begin{array}{l}\text { Sound } \\
\text { speed } \\
(\mathrm{km} / \mathrm{e})\end{array}$ \\
\hline STLM-1 & 241 & 0.594 & 2.62 & 0.222 & 1.42 & 0.090 & 3.40 \\
\hline STLM-2 & 244 & .599 & 258 & .230 & 1.44 & .096 & 3.85 \\
\hline STLM-3 & 248 & .509 & 2.80 & .182 & 1.24 & .076 & 3.59 \\
\hline STLM-5 & 2.47 & A11 & (2.62) & .146 & 0.94 & .059 & - \\
\hline STLM-6 & 2.48 & .317 & 248 & .110 & 0.74 & .038 & - \\
\hline WTLM-1 & 2.44 & 0.700 & 2.68 & 0.265 & 1.74 & 0.110 & - \\
\hline
\end{tabular}
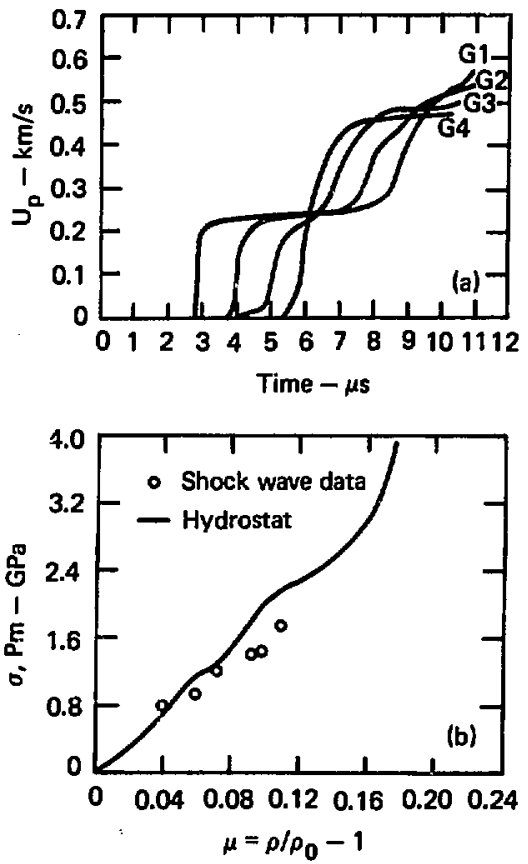

Figure 1I. Experimental dath for saturated Iodian limestome. (a) Particle velocity-tione hatories from ose experienent. (b) Hugonlot and bydrostatic compression dats. 


\section{DISCUSSION}

An examination of the profiles obtained from shock wave loading of thees eight: rocks indicates that all, except Weaierly granite and nugget sandstone, show an obvious dipendence of phase velocity upon strain rate of incubation time. Because of the similarity and the relative simplicity of their behavior, we will discuss nugget sandstone and Westerly granite firsi. The loading waves that propagate in Westerly granite and nugget sandstone are steady shocks, which means that losding occurs along a Rayleigh line. The unloading paths show some hysteresis in the stresscompression plane, but the corresponding volume of compression is consistent with that expected from the compaction or crushing of the initial dry porosity. Analysis of the shock wave data from these two materials suggests that each has a threshold stress for crushing of the rock matrix which surrounds the porcs. (This threshold stress in nugget sandstone is approximately $1.5 \mathrm{GPa}$; in Westerly granite it is between 2 and $3 \mathrm{GPa}$ ). At stresses below this threshold, deviations from linear or elastic behavior are small and are associated with the closing of the very thin microcracks, which account for about $1 / 3$ of the total porcsity in each of these two materials. At stresses above this threshold, the remaining porosity, which is present in the form of more nearly spherical pores, is eliminated as the rock matrix yields and collapses to fill the pores. In hydrostatic experiments on Westerly granite up to a mean stress level of 4.0 $\mathrm{GPa}$, no evidence of pore collapse has been observed. The reason for the discrepancy between these observations and those in the shock wave experiments may lie in the fact that shear stresses are present in the shoc: xperiments that would initiate pore coilapse at a ower stress level than in the hydrostatic experiment.

Blair dolomite and polycrystalline $\mathrm{NaCl}$ are similar to Westerly granite and nugget sandstone, in that both sets of rocks have small amounts of gasfilled porsity. However, unlike the two silicate rocks, Blair dulomite and polycrystalline $\mathrm{NaCl}$ propagate nonsteady state shocks.

In polycrystalline salt, a definite two-wave structure is formed. Neither of these waves is steady, although the second wave is more dispersive than the first. The first wave is associated with matrix yielding, i.e., plastic flow of the salt, while the dispertion of the econd wave is attributed to crushing of pores.

The norsteady wave propagation in Blair dolomite manifests itself in the form of a single loading wave with two components, which is different from the two-wave loading seen in polycrystalline $\mathrm{NaCl}$. The first part of the twocomponent wave in Blair dolomite is steady, but the second part spreads as it propagates.

Our observation of nonsteady behavior at stress levels between 0.24-5.33 GPa in Blair dolomite is in contradiction to the observation of Grady et al. 11.12 According to their data, non-steady behavior occurred only at stress levels above $2.5 \mathrm{GPa}$. This aifference in behavior is presently unexplained. Neverth.less, on the basis of our data, we have drawn several conclusions. The first component, i.e, the steady part, of the wave represents a threshold stress for matrix failure, whish is a complicated function of the applied stress. The second part of the loading wave is nonsteady and this nonsteady behavior probably results from the compaction of available porosity but may result from some timedependent yielding process.

Dry Mt. Helen tuff and dry Indiana limestone have greater porosity than the rocks and salt discussed. Under shock wave loading the behavior of these two highly porous rocks is very similar. Both materials exhibit nonsteady wave propagation with a precursor wave having an amplitude of approximately $0.25 \mathrm{GPa}$. The front of this precursor wave travels at longitudinal sound speed in the material and is dispersive, producing a ramp-like structure as it propagates. This precursor wave is believed to result from the hydrodynamic instability caused by dynamic yielding of the rock matrix. Once this yielding process has started, the rock undergoes a time-dependent, irreversible conpaction of the existing porosity. This process gives rise to a highly dispersive, second loading wave that eventually brings the rock to its final loeded state. The effect of such compaction is also exhibited in the behavior of the subsequent unloading process. In addition, unloading paths are similar for these two highly porous rocks and, in the stress-compression plane, are displaced significantly from the loading path. Thus the loading-unloading cycles show a good deal of hysteresis, which suggests a high degree of irreversible compaction. The Mt. Helen tuff shows nearly complete compaction of the available porosity after release from $3 \mathrm{GPa}$, and the limestone shows approximately $50 \%$ compaction after release from $4 \mathrm{GPa}$. This difference in behavior may be the result of a different distribution of pore sizes, i.c., there are more spherical pores in the limestone, or may be linked, in some complex way, to polymorphism in limestone. When the shock wave 
data for these two dry porous materials are compared with measured hydrostats, the similarities in behavior seem to disappear. In Mt. Helen tuff, the stress-compression Hugoniot begins above the hydrostat, then crosses into the region below it at a stress of about $1.2 \mathrm{GPa}$. However, in Indiana limestone, the Hugoniot remains above the hydrostat, and at a stress separation of about twice, that expected from a combination of quasi-static strength and pressure measurements. (This approximates the separation expected if strength were increased about $10 \%$ per decade of strain rate). Considering the Mt. Helen tuff data alone, the crossing of the two sets of data could result from shear enhanced compaction in the dynamic experiments. Such interpretation, however, raises several questions. For example, why don't the curves (Hugoniot and hydrostat) cross at a lower stress, i.e., nearer to the matrix failure stress? Why don't the two curves cross in dry Indiana limestone? The answers to these questions are closcly related to the time-dependent processes that are occurring in these complex rock types. Obviously, pore collapse in highly porous rock is a sensitive function of time because it involves movement of mass over relatively large distances through complex arrangements of pores. Limestone introduces an additional complexity because it can undergo polymorphism (another time-dependent process) in the stress range of this experimental investigation.

Finally, we ask why Blair dolomite, polycrystalline $\mathrm{NaCl}$, dry $\mathrm{Mt}$. Helen tuff, and dry Indiana limestone all propagate nonsteady waves that are partially attributed to pore collapse phenomena, while Westerly granite and nugget sandstone do not appear to do so. Actually all these rocks propagate nonsteady waves. In the silicate rocks, however, the complete pore collapse process is spread over a larger stress regime. Coupled with the small initial porosity and the greater strength of the matrix, the Westerly granite and nugget sandstone are much more nearly elastic than the other rocks. The fact that nonsteady wave propagation is observed in these rocks clearly indicates that on-going processes require time durations equal to or greater than the rise times of the initial input shock wave to establish mechanical equilibrium.

Of the two saturated porous rocks, Mt. Helen tuff is far less complicated. Comparison of shock wave and hydrostatic data suggests that this rock loses its strength under plane shock wave loading because of pore pressure buildup. However, at stress above $1.2 \mathrm{GPa}$, where water is converted to ice VI, the behavior of this saturated rack appears to hecome time dependent because the shock wave data show no indication of the volume compaction expected for such transformation. This suggests the possibility of a metastable form of water existing under dynamic conditions.

In saturated Indiana limestone, a comparison of shock wave and hydrostatic data suggests that timedependent effects are dominating the response of this material under shock wave loading at stresses both below and above the liquid water-to-ice VI transition point.

Historically, constitutive models used in computer codes to predict dynamic response have been bäsed primarily on experimental data generated under quasi-static conditions. Shock wave experiments have been used basically as tests against which constitutive models in the codes are checked by running problems that simulate a laboratory experiment. In some materials, quasi-static laboratory data (strain rates of $10^{-4}-10^{-3} \mathrm{sec}^{-1}$ ) and shock wave data (strain rates of $10^{5}-10^{7} \mathrm{sec}^{-1}$ ) agree. In these cases, the quasi-static data can confidently be used in developing models to describe dynamic phenomena that involve strain rates of $10-10^{5} \mathrm{sec}^{-1}$. However, some materials exhibit arsent rate phenomena that are not present under quasi-static conditions. Dry porosity and phase transformation apparently contribute to this rate phenomena. Therefore, extreme caution should be exercised in using data obtained quasi-statically in constitutive theory to calculate the behavior of rocks under dynamic sonulitivis whenever any significant amount of dry porosity or a phase transformation is present. Similarly, if dynamic: data were used to develop a constitutive model and calculations of static problems were performed : ind then tested against the results of quasistatic experiments, some discrepancies could be expected. Therefore, caution should be exercised where data obtained dynamically in constitutive theory is used in the calculation of the behavior of rocks under static conditions. In actual application, this latter case has not arisen. 


\section{CONCLUSIONS}

Bayed on our analysis of the data obtained from plece shock wave experiments we can draw the following conclusions:

1. Of the eight rocks studied, only Westerly granite and nugget sandstone appear to propagate steady waves, i.c., are time in. dependent in their behavior.

2. Weaterly granite and nuggei sandstone show evidence of a change of character at $2-3 \mathrm{GPa}$ and $1.5 \mathrm{GPa}$, reapectively. The stress at which this change of character is observed has been interpreted as a threshold stress for the collepse of pores.

3. In Blair dolomite and polycrystalline $\mathrm{NaC}$ ! time-dependent behavior is observed and attributed to the time required to close the small amount of available porosity.

4. The highly porous dry rocks, Mt. Helen tuff and Indiana limestone, are strongly timedependent materials. This characteristic would seem to preclude the use of quasi-static data in constitutive models that are used to calculate dynamic processes.

5. The water in water-saturated rocks shows no indication of transformation to the higher pressure ice phases. This suggests the possibility of a metastable form of water existing under dynamic conditions.

\section{ACKNOWLEDGMENTS}

The authors would like to acknowledge the invaluable technical help of G. Hi ikman, J. Taylor, G. Bearson, R. Schnetz, G. Thoripson, W. Stutler, and $W$. Mumper. The many suggestions and con- tributions to this work of H. Rodean, J. Hearst, and S. Spataro are also very much appreciated. The comments of R. N. Schock on this manuscript have been very helpful. 


\section{REFERENCES}

1. G. D. Andersoin and D. B. Larson, Shock Wave Studies of Subbituminous Coals, Lawrence Livermore Laboratory, Livermore, Calif., UCRL-51996 (1976).

2. D. B. Larson, G. D. Bearson, and J. R. Taylor, Shock Wave Studies of Ice and Two Frozen Soils, North American Contributions, presented at Second International Conference on Permafrost, Yakutak, USSR, 1973 (National Academy of Science, Publ. ISEN-0-309-22115-4, 1973).

3. M. Cowperthwaite and R. F. Williams, "Determination of Constitutive Relationships with Multiple Gauges in Nondivergent Waves," J. Appl. Phys. 42, 456 (1971).

4. W. J. Murri and C. W. Smith, Eguation of State of Rocks, Stanford Research Iristitute, Interim Technical Report PGU-66i8 (1970).

5. R. P. Swift, The Dynamic Response of Westerly Granite to Spherical Stress Waves, Defense Atomic Suppori Agency, DASA-2717 (1971).

6. D. B. Larson, The Relationship of Rock Properties to Expiosive Energy Coupling, Lawrence Livermore Laboratory, Livermore, Calif., UCRL-52204 (1977).

7. J. T. Rosenberg, Dynamic Shear Strength of Shock-Loaded-Granite ar. 'Pol'. . 'ystalline Quartz, Stanford Research Institute, DASA-2718 (1972).

8. H. C. Heard, A. E. Abey, B. P. Bonner, and R. N. Schock, "Mechanical Behavior of Dry Westerly Granite at High Pressure," Lawrence, Liver" - Livorntory, Livcrmore, Calif., ICRL-51642 ".man).

9. E. S. Sprunt and W. F. Brace, "Direct Observation of Microcavities in Crystalline Rocks," Int. J. Rock Mech. Min. Sci, Geom;zch. 11, 139 (1974).

10. R. N. Schock, A. E. Abey, B. P. Bonner, A. Duba, and H. C. Heard, Mechanical Properties of Nugget Sandstone, Lawrence Livermore Laboratory, Livermore, Calif., UCR.L-51447 (1973).

11. D. E. Grady, R. E. Hollenbach, K. W. Schuler, and J. F. Callender, "Strain Rate Dependence in Dolomite Inferred from Impact and Static Compression Studies," J.G.R. 82, 1325 (1977).

12. D. Grady and R. E. Hollenbach, "High Strain Rate Studies in Rock," Geophysical Research Letters 4, 263 (1977).

13. H. C. Heard, A. Duba, A. E. Abey, and R. N. Schock, Mechanical Properties of Blair Dolomite, Lawrence Liv jrmore Laboratory, Livermore, Calif., UCRL-51465 (1973).

14. H. C. Heard, A. E. Abey, B. P. Bonner, and A. Duba, Stress Strain Behavior of Polycrystalline NaCl to 3.2 GPa, Lawrence Livermore Laboratory, Livermore, Calif., UCRL-51743 (1975).

15. H. C. Heard, B. P. Bonner, A. Duba, R. N. Schock, and D. R. Stephens, High Pressure Mechanical Properties of Mt. Helen, Nevada Tuff, Lawrence Livermore Laboratory, Livermore, Calif., UCID-16261 (1973).

16. W. J. Murri, D. E, Grady, and K. D. Mahrer, Equation of State of Rocks, Stanford Research Institute, Final Rept. PYU-1883 (1975).

17. P. C. Lysne, "A Comparison of Calculated and Measured Low-Stress Hugoniots and Release Adiabats of Dry and Water Saturated Tuff," J.G.R. 75, 4375 (1970).

18. H. C. Heard, A. E. Abey, and B. P. Bonner, High Pressure Mechanical Properties of Indiana Limestone, Lawrence Livermore Laboratory, Livermore, Calif., UCID-16501 (i974). 